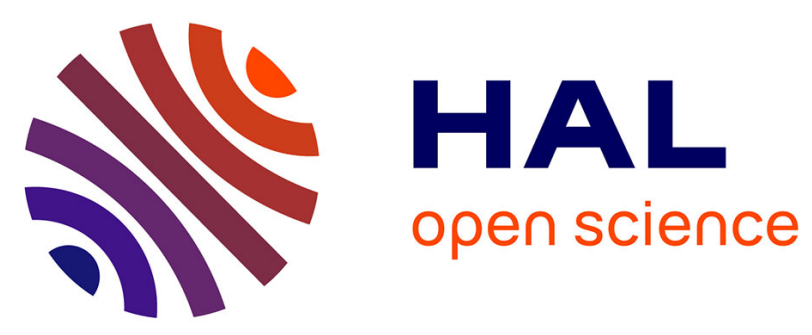

\title{
Temporal fluctuations in zooplankton size, abundance, and taxonomic composition since 1995 in the North Western Mediterranean Sea
}

\author{
Guillaume Feuilloley, Jean-Marc Fromentin, Claire Saraux, Jean-Olivier
} Irisson, Laetitia Jalabert, Lars Stemmann

\section{To cite this version:}

Guillaume Feuilloley, Jean-Marc Fromentin, Claire Saraux, Jean-Olivier Irisson, Laetitia Jalabert, et al.. Temporal fluctuations in zooplankton size, abundance, and taxonomic composition since 1995 in the North Western Mediterranean Sea. ICES Journal of Marine Science, 2022, 79 (3), pp.882-900. 10.1093/icesjms/fsab190 . hal-03374991

\section{HAL Id: hal-03374991 \\ https://hal.science/hal-03374991}

Submitted on 18 Nov 2021

HAL is a multi-disciplinary open access archive for the deposit and dissemination of scientific research documents, whether they are published or not. The documents may come from teaching and research institutions in France or abroad, or from public or private research centers.
L'archive ouverte pluridisciplinaire $\mathbf{H A L}$, est destinée au dépôt et à la diffusion de documents scientifiques de niveau recherche, publiés ou non, émanant des établissements d'enseignement et de recherche français ou étrangers, des laboratoires publics ou privés. 
Temporal fluctuations in zooplankton size, abundance and taxonomic composition since 1995 in the North Western Mediterranean Sea

\author{
Guillaume Feuilloley ${ }^{1}$, Jean-Marc Fromentin ${ }^{1}$, Claire Saraux ${ }^{2}$, Jean-Olivier Irisson ${ }^{3}$, Laetitia \\ Jalabert ${ }^{3}$ and Lars Stemmann ${ }^{3}$ \\ ${ }^{1}$ MARBEC, Univ Montpellier, CNRS, Ifremer, IRD, Sète, France \\ ${ }^{2}$ Univ Strasbourg, CNRS, IPHC UMR 7178, DEPE, 67000 Strasbourg, France \\ ${ }^{3}$ LOV, Observatoire Océanologique, UMR7093, UPMC Univ Paris 06, 06234 \\ Villefranche/mer, France
}

\title{
Abstract
}

In the Gulf of Lions, small pelagic fish have shown reduced body size and body condition after 2007 that would result from changes in zooplankton community. We therefore examined zooplankton density, body size and taxonomic composition at the closest long-term monitoring station (19952019): the coastal Point-B. To cover a broader spectrum of zooplankton community, samples obtained from two nets, the WP2 $(200 \mu \mathrm{m}$ mesh size $)$ and the Regent $(690 \mu \mathrm{m})$, were analysed with the imaging Zooscan method. One important result was the high stability through time of the zooplankton community. No long-term monotonous trends in density, size and taxonomic composition were detected. Interannual variations in zooplankton size and density were not significantly correlated to any environmental variable, suggesting the possible importance of biotic interactions. Still, an increase in temperature was followed by a sharp decrease of zooplankton density in 2015, after which only gelatinous groups recovered. No change in the zooplankton community was detected around 2007 to support bottom-up control on small pelagic fish. Whether this derives from different local processes between the Gulf of Lions and Ligurian Sea cannot be excluded, highlighting the need for simultaneous monitoring of different ecosystem compartments to fully understand the impact of climate change. 


\section{Introduction}

Zooplankton is most often very responsive to environmental changes and could consequently impact upper trophic levels with possible repercussions up to top-predators through different mechanisms (Beaugrand \& Kirby, 2010; Cury et al., 2000; Lynam et al., 2017). Changes in plankton phenology (Aberle et al., 2012; Thackeray et al., 2010; Winder et al., 2012) can for instance directly affect planktivorous species recruitment, either positively (match) or negatively (mismatch) (Cushing, 1990). Warming could also decrease net primary production (Bopp et al., 2013) and favor smaller phytoplankton (Daufresne et al., 2009) and zooplankton (Kudela et al., 2006; Medellín et al., 2016) species, modifying the availability of energetic resources in food webs as small zooplankton individuals are generally less energetic than large ones (Barroeta et al., 2017). In upwelling systems, sardine and anchovy regime fluctuations have indeed been related to the size of zooplankton, sardine favoring smaller prey due to higher filtration capacity compared to anchovy (Tam et al., 2008; Van der Lingen et al., 2006). A recent experimental study further showed that Mediterranean sardines feeding on bigger pellets $(1.2 \mathrm{~mm})$ were in better body condition (a proxy for energy reserves) and displayed higher growth rate than those feeding on smaller particles $(0.1 \mathrm{~mm})$, probably because of a change to a more costly feeding behavior (Queiros et al., 2019), again highlighting the importance of plankton size. In the Gulf of Lions and the bay of Biscay, changes in the zooplankton community and especially the zooplankton quality are suspected to be one of the main drivers of changes in fish size structure and mean body condition (Brosset et al., 2016; Saraux et al., 2019; Véron et al., 2020). Understanding how the plankton community varies in terms of taxonomic composition, body size and density is of primary importance to understand potential impacts on higher trophic levels, especially in a context of climate change.

The Mediterranean sea is an oligotrophic semi-enclosed basin under strong anthropic impact (The MerMex Group et al., 2011). In the last 2 decades, different studies highlighted important changes in size, abundance, body condition or spatial distribution of Mediterranean fish populations (Brosset et al., 2017; Sabatés et al., 2006; Saraux et al., 2019; Tsikliras, 2008; Van Beveren et al., 2014). Particularly in North Western Mediterranean sea (NWMS), important demographic changes have been recorded in small pelagic fish since 2007 (Van Beveren et al., 2014; Brosset et al. 2017). Different hypotheses have been formulated and investigated, but top-down controls (due to overfishing or natural predation), emigration of largest individuals or epizootic diseases have all been refuted (Queiros et al., 2018; Van Beveren, et al., 2016a,b, 2017), so that the hypothesis of a bottom-up control has been 
suggested as the most probable underlying mechanism (Brosset et al., 2016; Saraux et al., 2019).

Unfortunately, long time series of zooplankton in the NW Mediterranean are scare. Using the longest zooplankton time series in the neighboring Ligurian Sea, several studies have shown interannual variability possibly related to large-scale climatic forcing, especially the North Atlantic Oscillation (García-Comas et al., 2011; Molinero et al., 2005; Vandromme et al., 2011; Fullgrabe et al., 2020). According to these studies, interannual variations in winter conditions led to changes in the availability of nutrients resulting in different spring bloom intensities. During favorable years (in the 1980's and early 2000's), increased primary production would favor zooplankton production (especially copepods) for the rest of the year. Coupled atmosphere/ocean/biogeochemical modeling of the central NW Mediterranean sea supported the hypothesis of interannual control of plankton communities by deep winter mixing (Auger et al., 2014). Interannual interactions between filter-feeding gelatinous zooplankton and copepods were suggested to be another key factor (Molinero et al., 2005). The former are more efficient grazers of small phytoplankton than the latter and would overcompete them during warm years, when pico- and nanophytoplankton dominate (Licandro et al., 2006). Finally, it has also been suggested that carnivorous gelatinous, such as Chaetognatha or Siphonophorae could also have an impact by increasing the top down pressure on copepods (Molinero et al., 2008b).

Nonetheless, these studies had investigated zooplankton fluctuation either until 2005 in the northern coastal station (point B) or from 2004 to 2016 in the southern station (Stareso station), but not on a period spanning several years before and after 2007, i.e. when the main changes in NW Mediterranean small pelagic fish population were observed (Saraux et al., 2019). Moreover, most studies had focused on zooplankton densities and did not investigate potential changes in size distribution of the NW Mediterranean zooplankton.

The main objective of this work was then to study long-term, interannual and seasonal variations in zooplankton density, body size and taxonomic composition to identify potential changes since 1995. For the first time at the point B station, the long-term variations of zooplankton was studied based on 2 different nets (the WP2 with a small mesh size $(200 \mu \mathrm{m})$ and the Regent focusing on larger individuals (mesh size of $690 \mu \mathrm{m}$ ) in order to cover a broader spectrum of the zooplankton community. A focus was made on the crustaceans because they are the most abundant zooplankton and the principal prey of many small pelagic fish in the NW Mediterranean sea (Brosset et al., 2016; Plounevez \& Champalbert, 2000). The variability of gelatinous carnivorous and gelatinous filter-feeders was also examined, as 
these two groups could potentially interact with crustaceans through competition or predation.

114 We finally tried to understand the interplays between crustaceans abundance, taxonomic composition, size spectra and environmental changes.

\section{MATERIAL AND METHODS}

\section{Sample collection}

119 Zooplankton samples were collected weekly at Point B $\left(43^{\circ} 41.10^{\prime} \mathrm{N}, 7^{\circ} 18.94^{\prime} \mathrm{E}\right.$; $85 \mathrm{~m}$ water depth), a coastal monitoring station at the entrance of the bay of Villefranche-sur-Mer (NW Mediterranean Sea, France). Sampling was done by vertical tows (75 m deep to surface) of a Regent net (mesh size of $690 \mu \mathrm{m}$, mouth aperture of $0.785 \mathrm{~m}^{2}$ ) and WP2 net (mesh size of $200 \mu \mathrm{m}$, mouth aperture of $0.25 \mathrm{~m}^{2}$ ). For the present study, 919 samples collected once to 4 times a month from 1995 to 2019 were used for Regent net and 666 for WP2, from 2004 to 2019. All samples were manually fractionated with a Motoda box and then analysed with the Zooscan/Zooprocess system (Gorsky et al., 2010). Samples were fractionated at different levels, depending on zooplankton abundance in the sample, so as to keep around 1500 and 500 individuals in the samples for the WP2 and the regent nets, respectively. This process allows having a picture for each individual (avoiding superimposed or touching individuals), from which the identification and size measurements can be performed. Identification was performed using automatic recognition, followed by the validation of each picture by an expert. All the zooplankton data are available on the EcoTaxa platform (https://ecotaxa.obsvlfr.fr/).

\section{Taxonomy in the WP2}

Because of the small size of individuals in the WP2 net, taxonomic identification at fine level was not possible in the frame of this study. 15 groups that presented the finest taxonomic identification homogenous for the whole time were finally retained, i.e., "Eumalacostraca", "Cladocera ", "Ostracoda", "Copepoda" and "Other_Crustacea" for the crustaceans ; "Chaetognatha", "Siphonophorae", "Other Hydrozoa", "Salpida", "Doliolida" and "Appendicularia" for gelatinous species and finally "Harosa", "Annelida", "Mollusca" and "Other zooplankton". The gelatinous were grouped in two functional groups, the "herbivorous" filter feeders (Doliolida, Salpida and Appendicularia) and the carnivorous (Chaetognatha, Siphonophorae and Other hydrozoa) (Acuña, 2001; Dallot et al., 1988).

\section{High resolution taxonomy in the Regent}


146 In the Regent, a high resolution taxonomic identification was possible, especially for 147 crustaceans, because of a greater size of the individuals allowing a better recognition 148 compared to smaller one. The taxonomy was determined as a compromise between the 149 resolution allowed by the image quality, preventing high resolution taxonomy for small 150 individuals, and the necessity to aggregate rare groups. Because the Calanoida order was 151 dominant (around $60 \%$ of crustaceans), analyses were performed mainly at the family level 152 for Copepoda, including: Calanidae, Centropagidae, Candaciidae, Metridinidae, Temoridae, 153 Acartiidae, Eucalanidae, Euchaetidae, Corycaeidae, Sapphirinidae, Oithonidae and 154 Oncaeidae. Other small Copepoda families (e.g. Clausocalanidae \& Paracalanidae) that 155 could not be distinguished with the image resolution were pooled in Other_Calanoida. Decapoda, Amphipoda, Mysida and Euphausiacea were however only identified at the order

157 158 159 160 161 162 levels. Finally, a "Other_Crustacea" group was also kept, representing mainly individuals identified at a low taxonomic resolution, but around $90 \%$ of the individuals of this group were identified as Eumalacostraca, at the subclass level. For comparison purposes, Regent results are presented both at the fine taxonomy level and at the same taxonomy level as the WP2 net.

\section{Time series analyses of the zooplankton density}

Because both changes in plankton phenology and density could affect upper trophic levels, we investigated crustaceans and gelatinous (herbivorous and carnivorous) densities at a monthly time scale. Data were expressed in individuals $/ \mathrm{m}^{3}$ and log-transformed to stabilize the variance (Curran-Everett, 2018). A wavelet analysis was performed to quantify the main patterns of variability (Carey et al., 2016; Chatfield, 2003). Wavelet analysis is a frequencyanalysis technique that can be used to reveal the frequency components of signals and identify where a certain frequency exists in the temporal domain (e.g. seasonal signal would be seen at a frequency of 12 months). By looking for regions where the Wavelet Power Spectrum (WPS) is of large power, we can determine which features of the signal are important. The significance of the wavelet spectrum was performed against white noise, as the time series displayed variance at both high and low frequencies (Rouyer et al., 2008). The long-term trend was extracted with the Eigen Vector Filtering (EVF), which allowed us to estimate the percentage of variance associated to this trend (Ibanez \& Dauvin, 1988). To do this, a Principal Component Analysis (PCA) was performed on a matrix of the time series lagged from 0 to $\mathrm{n}$ time lags (in this study, $\mathrm{n}$ being equal to 36 months, which allowed us to investigate interannual variations without considering seasonal variability). The analyses were performed using the "pastecs" R package (Grosjean et al., 2014). The breakpoint analysis was 
performed to identify potential regime shifts (i.e. major discontinuities) in the time series using the "strucchange" $\mathrm{R}$ package and an algorithm testing structural changes in time series (Kleiber et al., 2002). Optimal number of segment partitions was based on Bayesian Information Criterion (BIC) in order to compute only the most relevant changes (Schwarz, 1978).

\section{Time series analyses of the zooplanktonic community}

To study the variations in the composition of the zooplanktonic community, monthly time series of densities of each group were constructed (see Sections 2.2 and 2.3). Monthly densities of each group were then plotted on stacked plots to depict both the interannual variations, the phenology of the zooplanktonic community and the proportion of each group. The long-term trends of each group were further extracted by means of EVF analysis (see above). Note that the proportion of each group per year (or month) was calculated on the raw data (without log transformation) and represented in "stacked plot" as the log density of total zooplankton multiplied by the proportion of each group.

\section{Time series analyses of crustaceans size spectra}

Because crustaceans are mostly ellipsoid, size of each individual was defined as the primary axis of the best fitting ellipse calculated during the Zooprocess (Gorsky et al., 2010; Romagnan et al., 2016). A sensitivity analysis was run to determine the minimal number of individuals within a sample to perform a reliable size spectrum. The results led us to keep a minimum of 200 and 45 individuals/sample for the WP2 and the Regent, respectively (See ESM - Figure S1). Monthly and annual size spectra were then computed by means of Normalized Density Size Spectra (NDSS), which is similar to the well-known Normalized biomass size spectra (Sheldon et al., 1977; Zhou et al., 2010), but based on density instead of biomass. To do so, the density of each size class was calculated and divided by the width of the size class in order to normalize the spectra. Size classes increased each time by a factor of 1.3 in order to have both details in smaller size and avoid empty size classes in higher body size. Analyses based on monthly crustaceans size spectra, investigating the distribution of all size spectra mode from 1995 to 2019 for Regent and from 2004 to 2019 for WP2 showed that the nets accurately sampled individuals measuring at least $1.5 \mathrm{~mm}$ and $0.65 \mathrm{~mm}$ for the Regent and the WP2 respectively (see ESM for details). For that reason, individuals lower than $1.5 \mathrm{~mm}$ for Regent and $0.65 \mathrm{~mm}$ for WP2 were not considered in any of the following analyses. For both nets, the upper limit of spectra (2.7 mm for WP2 and $3.7 \mathrm{~mm}$ for Regent) was defined as the one representing at least $1 \%$ of total individuals and contained all the individuals larger than this limit. For each monthly spectrum, the slope was estimated through 
214 a linear regression. The time series of the slopes of the monthly NDSS were finally 215 constructed and analysed through EVF to extract the trend (see above) and breakpoint analysis to identify potential regime shifts (i.e. major discontinuities) in the time series. The breakpoint analysis was performed using the "strucchange" $\mathrm{R}$ package and an algorithm testing structural changes in time series (Kleiber et al., 2002). Optimal number of segment partitions was based on BIC criterion in order to compute only the most relevant changes. Additional analyses based on functional PCA have been further performed and showed that the slopes of the NDSS carefully tracked changes in size spectra of the zooplanktonic community collected by the WP2 or by the Regent (see ESM for further details).

\section{Dealing with missing data}

224 The minimal number of individuals by sample necessary to construct reliable size spectrum (see above) led to some months with missing values, i.e., 14 of the 300 months in the slopes time series of Regent were missing, while 6 of the 192 months were missing for the WP2. 227 Furthermore, 4 of 192 monthly densities of the WP2 were also missing. Missing values were scattered over the whole period allowing to fill them with an algorithm based on iterative PCA from the MissMDA package (Josse \& Husson, 2012). First, the monthly time series was transformed in a year $\mathrm{x}$ month matrix and missing values were replaced by the mean of the variable (here the months). Then a PCA was performed and mean values inserted to fill missing data were replaced by the values estimated by the PCA. A second PCA was performed and values estimated by the first PCA were replaced by the one of the second PCA. Following this scheme, iterative PCA were performed until the values estimated stabilised.

\section{Environment data and analyses}

238 Because one of the objectives was to investigate whether the interannual variability observed in crustaceans density and size spectra could be explained by environmental parameters, we gathered a set of environmental variables that are known to affect plankton dynamics at both the local and the regional scales. All the local environmental data have been sampled weekly since 1995 at the same location as the plankton tows (the "Point B") at 5 different depths (1 $\mathrm{m}, 10 \mathrm{~m}, 20 \mathrm{~m}, 30 \mathrm{~m}$ and $50 \mathrm{~m})$. Water for nutrients and chlorophyll-a (Chl-a) analyses was sampled by Niskin bottles. Nitrate $\left(\mathrm{NO} 3 \mu \mathrm{mol} . \mathrm{l}^{-1}\right)$ and Silicate $\left(\mathrm{SiOH} 4 \mu \mathrm{mol} . \mathrm{l}^{-1}\right)$ nutrients were considered, but not Phosphorus because concentrations were at the limit of the detection threshold. Nutrient data at the $1 \mathrm{~m}$ and 50m layers were averaged, as those two depths were the only ones with complete data from 1995 to 2019. Chl-a was considered as a proxy of 
248 phytoplankton biomass and was averaged over the 5 available depths from 1 to $50 \mathrm{~m}$. A 249 Seabird SBE25 CTD was used to measure sea water temperature, which was also averaged over the 5 available depths from 1 to $50 \mathrm{~m}$. Finally, the stratification of the water column was calculated as the difference of water density between the $10 \mathrm{~m}$ layer and the $50 \mathrm{~m}$ layer, as in 252 Vandromme et al., (2011). All these environmental data were provided by SOMLIT 253 (http://somlit-db.epoc.u-bordeaux1.fr/bdd.php).

254 As winter water mixing could favour planktonic production (García-Comas et al., 2011; 255 Vandromme et al., 2011), a winter water mixing index was constructed. To do so, a PCA was 256 performed on the winter temperature, winter stratification (Vandromme et al., 2011), winter salinity and winter water density at the "Point B" (see ESM-Fig S2; Vandromme et al., 2011). All winter time series were constructed by averaging monthly values from December to March. The first axis of this PCA, which represented $56.6 \%$ of the total variance, was considered as the winter water mixing time series (see also Vandromme et al., 2011).

261 Finally, the large scale Western Mediterranean Oscillation (WeMO) index (Martin-Vide \& 262 Lopez-Bustins, 2006) was also considered, rather than the North Atlantic Oscillation (NAO) 263 index (as used in past studies, such as Molinero et al. 2005) because of its better representation of the environmental conditions of the North Western Mediterranean sea (Martin-Vide \& Lopez-Bustins, 2006; Martín et al., 2012). This index represents differences in standardized surface atmospheric pressure between San Fernando (Spain) and Padua (Italy) and reflects changes in regional weather conditions, especially in rainfall, river flow, wind strength and direction and temperature. Positive values of the index are associated to lower temperature and higher river flow and wind, thought to be favourable for plankton productivity (Martin-Vide \& Lopez-Bustins, 2006; Martín et al., 2012).

\section{size spectra}

274 To identify the potential relationships between environmental variables and the log-density or 275 size spectra of crustaceans, linear models (LM) were investigated, as these two biotic 276 variables were normally distributed. Environmental time series of local temperature, Chl-a, nitrate, silicate and the winter water mixing index as well as the WeMO index were used as explanatory variables. The linear models were based on annual time series for both the environmental and zooplanktonic variables to avoid the strong autocorrelation in the monthly time series due to the seasonal cycle. A stepwise forward and backward selection was run to select the most explanatory and significant variables based on corrected Akaike Information 
282 Criterion (AICc) (Burnham \& Anderson, 2004). Variance Inflation Factor values (VIF) were 283 checked in order to avoid multicollinearity between variables (Zuur et al., 2010). Finally, residuals and the goodness of fit of each model were then investigated through standard tests. Because relationships between zooplankton and environment could be nonlinear, potential synchronicity between breakpoints in environmental time series and zooplankton community was also investigated.

288 All the analyses presented above were conducted with R v. 3.4.1.

\section{RESULTS}

\section{Variability in zooplankton densities}

The long-term trend derived from the EVF explained a rather small proportion of the total variance of the Regent time series, i.e., between $7 \%$ and $20 \%$ but, the period between 2000 and 2005 was marked by higher densities mostly for the total zooplankton and gelatinous carnivorous and secondarily for the 2 other groups. The wavelet analyses performed on total zooplankton showed high power spectrum level (red plume on the wavelet plot) at the 12 months frequency highlighting an important seasonal cycle. Important noise was also observed in total zooplankton, revealed by the high power spectrum level in the 2 to 8 months frequencies (Figure 1-d). Both herbivorous and carnivorous gelatinous displayed some seasonality, but less marked than total zooplankton in the Regent. All 3 presented higher densities between April and June, but not all along the time series (Figure 1-b, c and d). However, crustaceans in the Regent did not display any clear seasonal cycle, but short-term variations, as observed in the wavelet analysis with high power spectrum from 2 to 12 months frequencies (even if highest densities seemed to occur generally in spring) (Figure 1-a). Concerning the WP2, the long-term trend derived from the EVF explained between $8 \%$ and $17 \%$ of the total variance of time series (Figure 1-e,f,g and h). The year 2015 appeared very particular, characterized by very low densities for the 3 groups (Figure 1-e, $f$ and $g$ ) as well as in total zooplankton abundance (Figure 1-h). Herbivorous and carnivorous gelatinous seemed to recover after 2015, their densities reaching similar (and even higher for herbivorous) levels than before (respectively around $3 \log \left(\right.$ ind. $\left.m^{-3}+1\right)$ and $2 \log \left(\right.$ ind. $\left.\left.m^{-3}+1\right)\right)$, but crustaceans densities stayed at lower values after 2015, at around $5.5 \log \left(\right.$ ind. $\left.m^{-3}+1\right)$. Total zooplankton and crustaceans time series were very similar in the WP2 and presented the same patterns of variation. The wavelet analyses showed high power spectrum level at the 12 months frequency highlighting the presence of a seasonal cycle (however less marked for herbivorous 
316 gelatinous). Strong variability was also present at high frequencies (2 to 8 months) for all four 317 time series, indicating also the presence of short-term variations or noise (Fig. 1). Intra-annual 318 (or seasonal) variability was indeed strongly present in crustaceans time series of the WP2, 319 with higher densities between February and May, up to $8 \log \left(\right.$ ind. $\left.m^{-3}+1\right)$ (Figure 1 - e). Note, 320 however, that this seasonality has been absent since 2015 during the period of lower densities, 321 as indicated by the lower power spectrum at the 12 months frequency after 2015 (Figure 1 322 e). The wavelet analyses did not detect any shift in the timing of the seasonal peak of the 323 crustaceans, herbivorous and carnivorous gelatinous of both the Regent and WP2 nets (Figure $3241)$. 

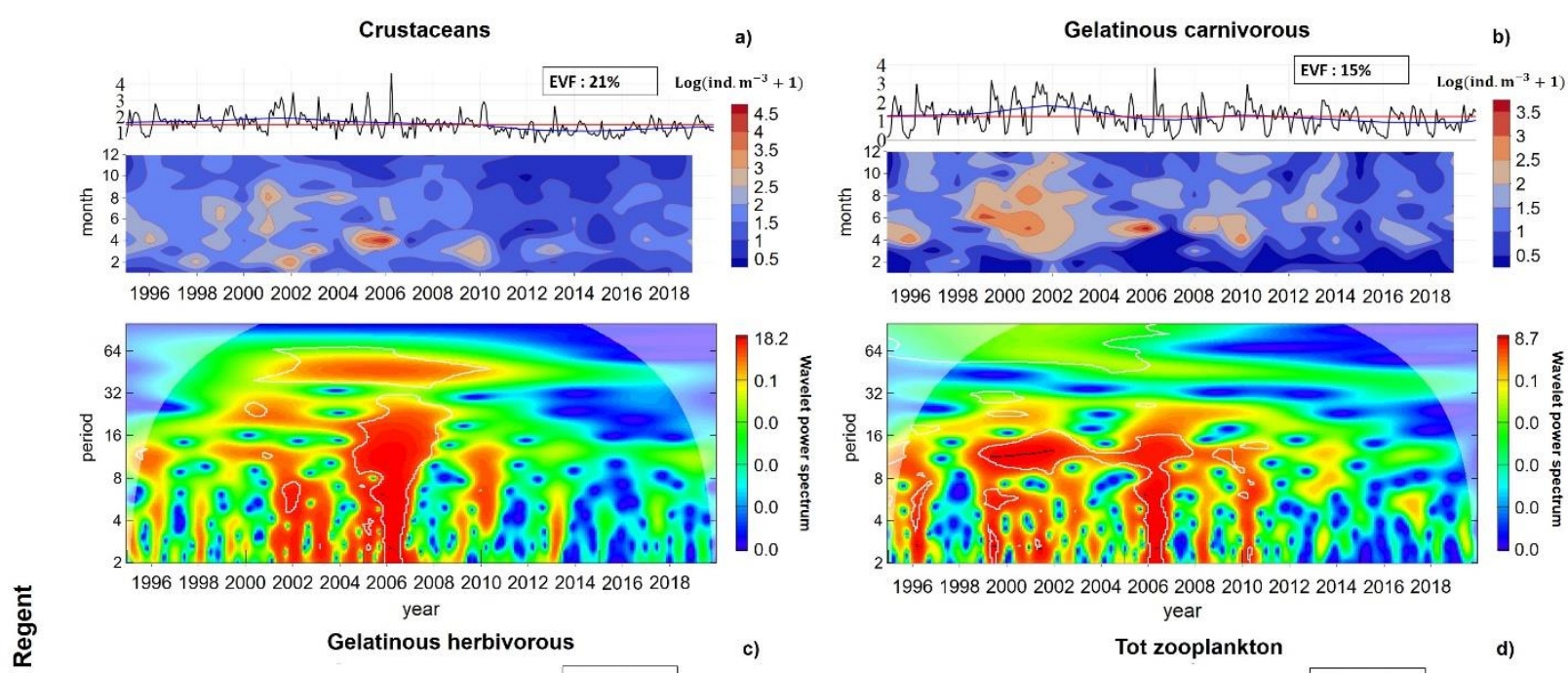

199619982000200220042006200820102012201420162018

Tot zooplankton

d)

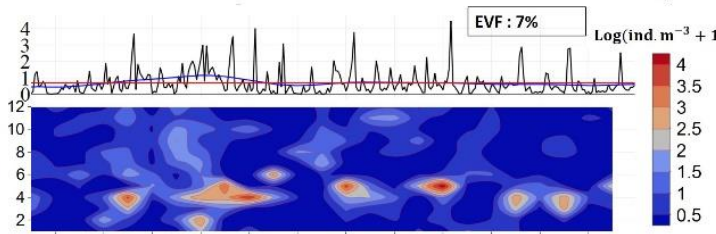

199619982000200220042006200820102012201420162018

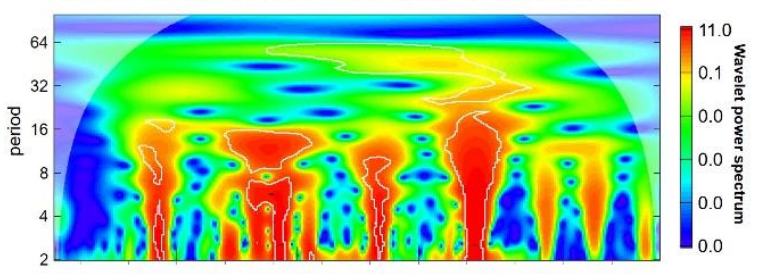

199619982000200220042006200820102012201420162018
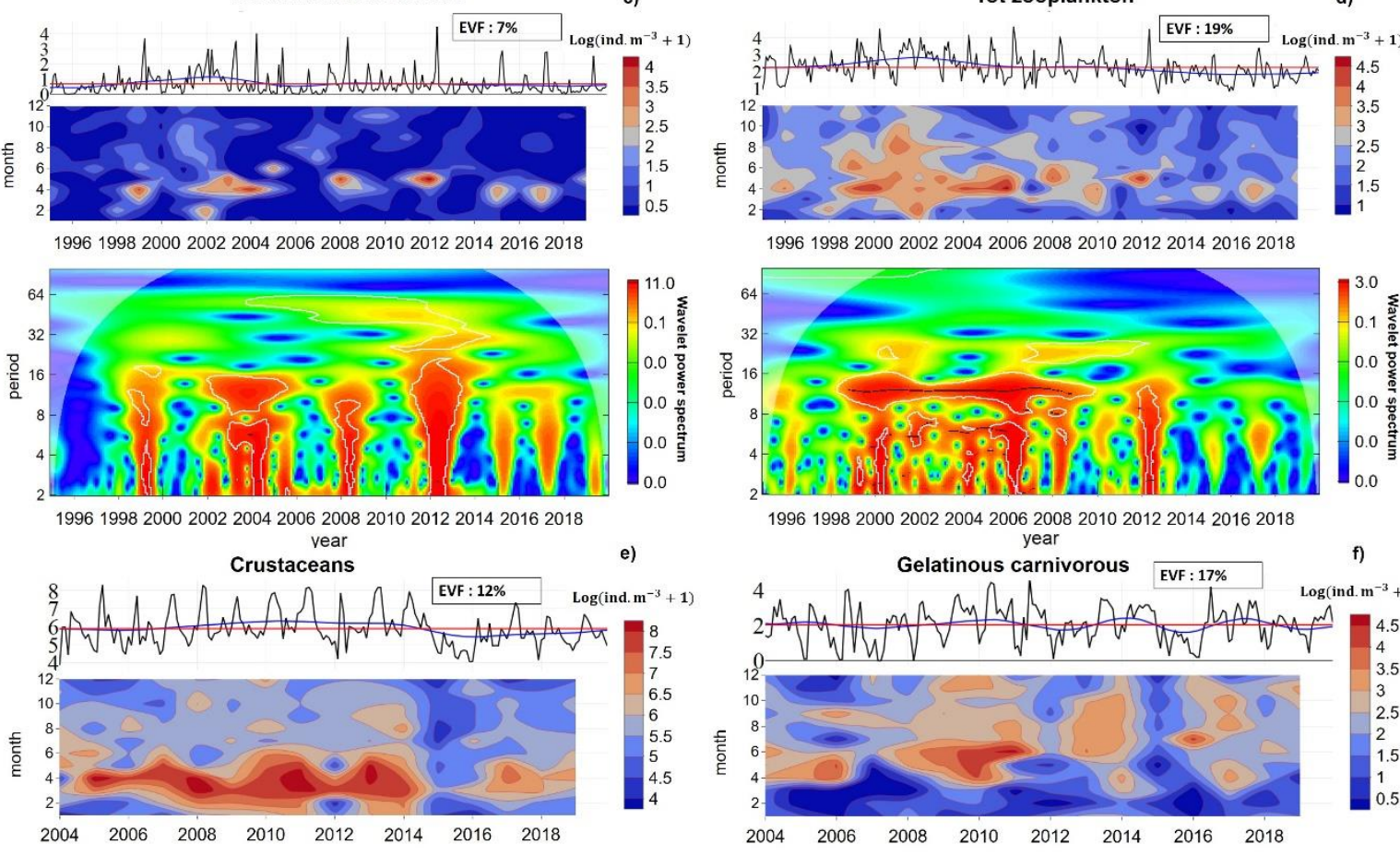

199619982000200220042006200820102012201420162018

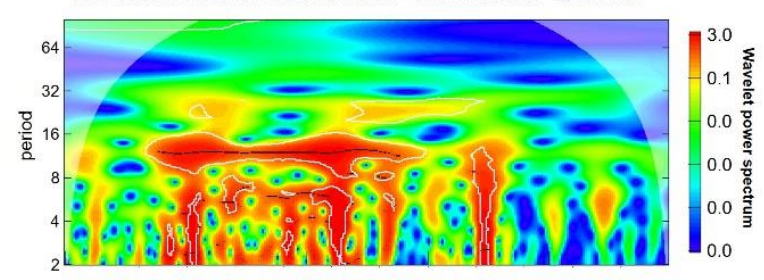

199619982000200220042006200820102012201420162018

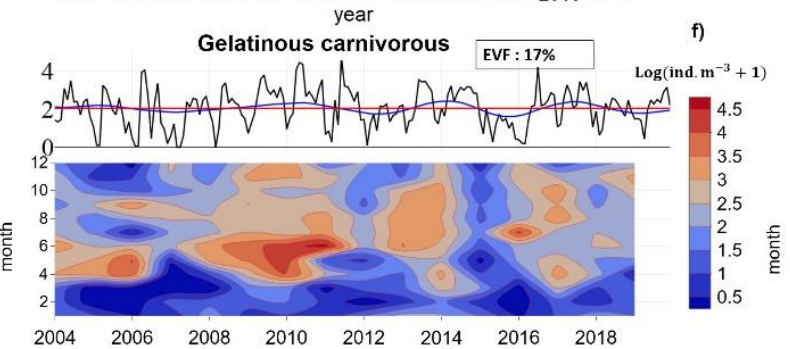

$\begin{array}{llllllll}2004 & 2006 & 2008 & 2010 & 2012 & 2014 & 2016 & 2018\end{array}$

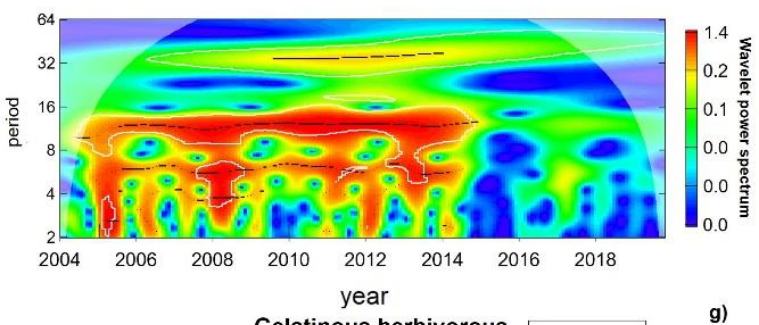

蒿
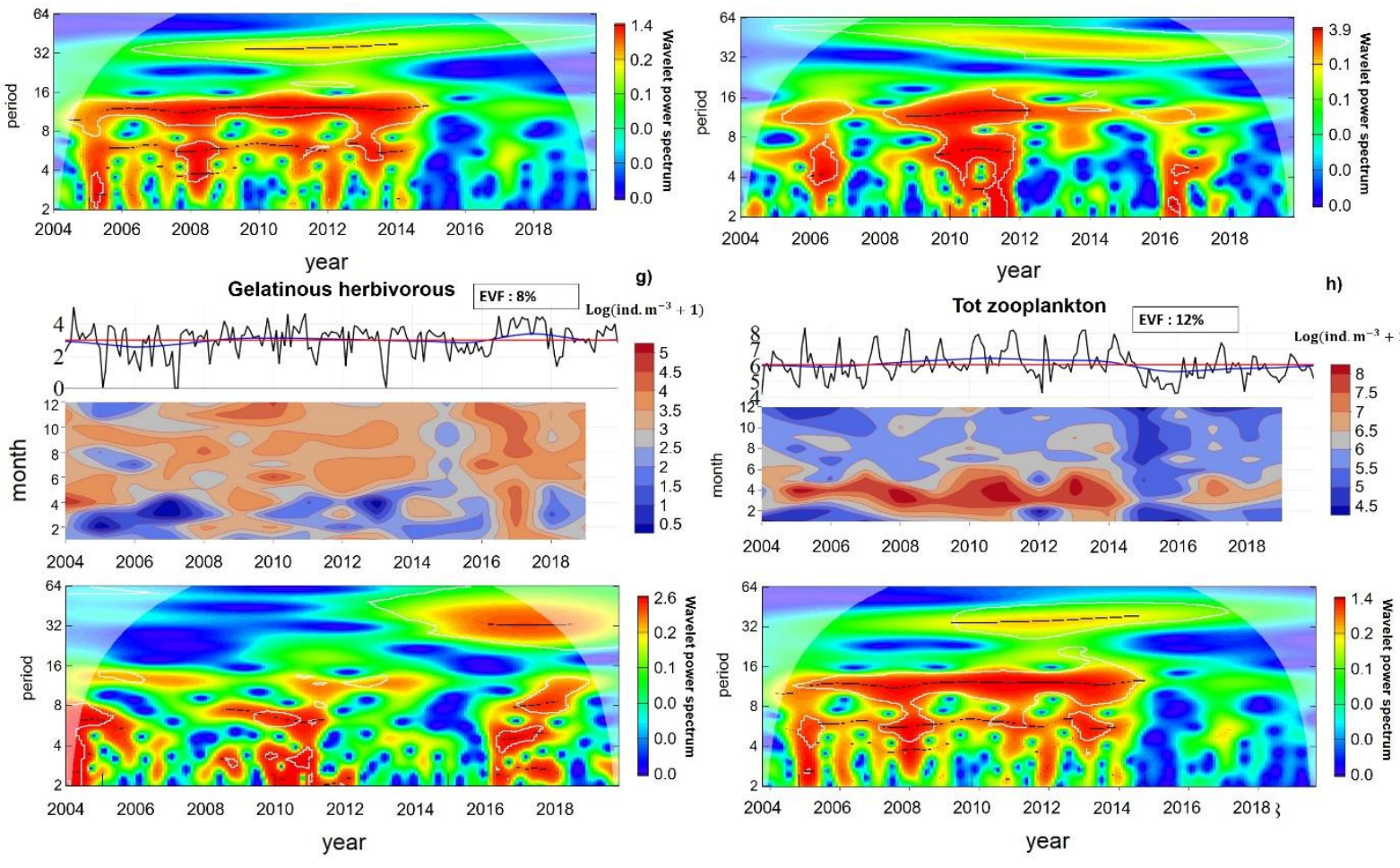
Figure1: Monthly log densities (ln (ind. $\left.\left.m^{-3}+1\right)\right)$ and wavelet analyses of crustaceans, gelatinous carnivorous and gelatinous herbivorous for Regent (upper panels) from 1995 to 2019 and for the WP2 (lower panels) from 2004 to 2019. For each block, the upper panel represents the monthly time series in black with the trend extracted with the EVF (in blue) and the mean over the whole period (in red). In the mid panel, the contour plot of the monthly densities. In the bottom panel, wavelet analyses performed on monthly densities. 


\section{Zooplankton taxonomic composition}

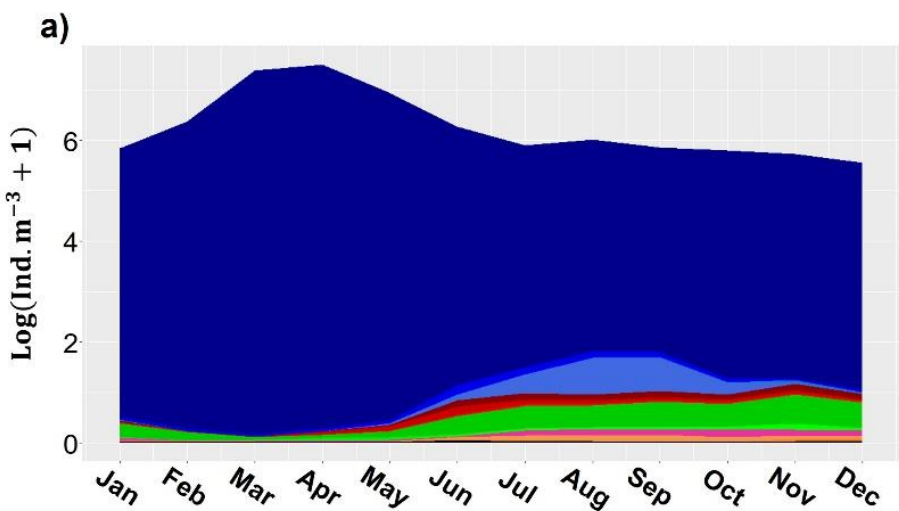

b)

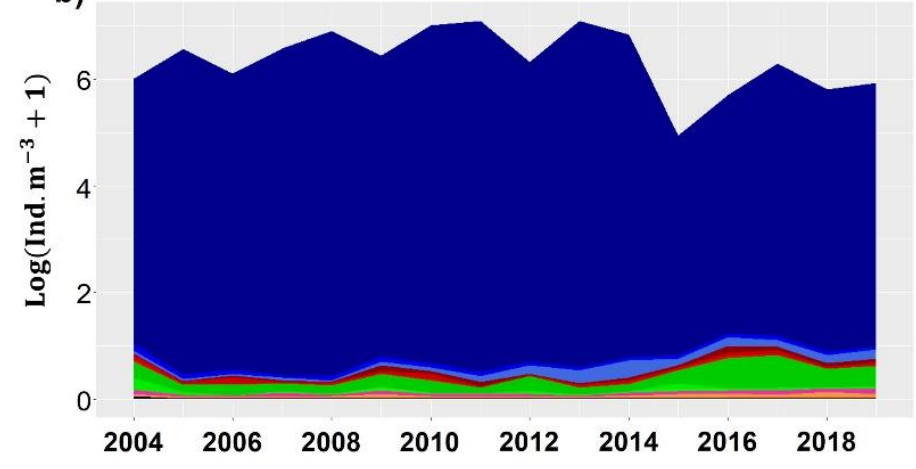

c)

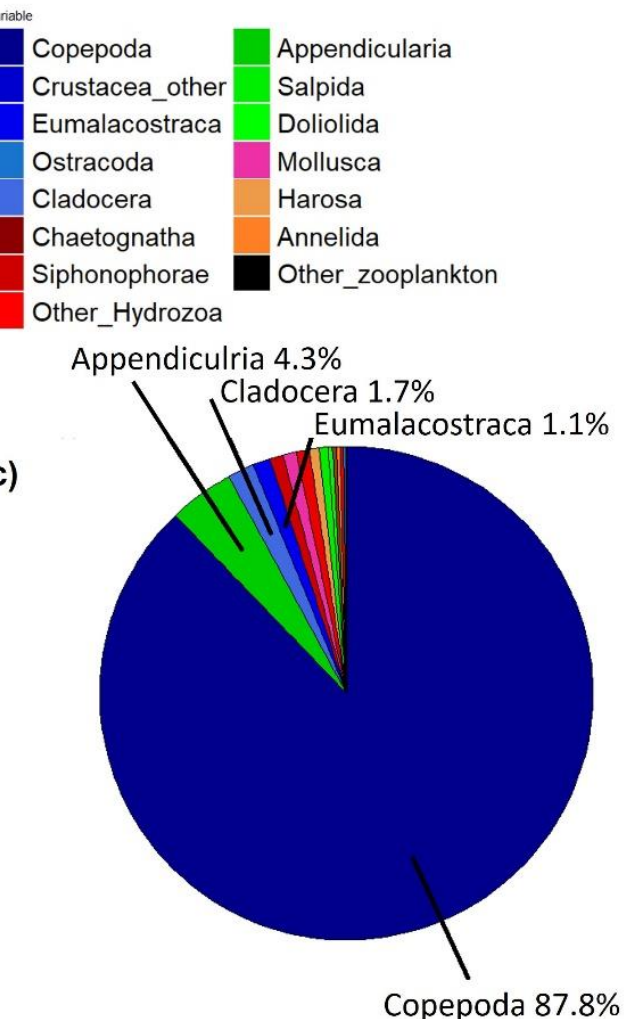

Figure 2: Stacked mean densities in the WP2 net (for individuals over $0.65 \mathrm{~mm}$ body length) of each group for each month (a), stacked yearly densities of each group from 2004 to 2019 (b) and mean proportion of the different groups for the whole period (c). Blue colors represent the crustaceans, red colors the gelatinous carnivorous and green colors the gelatinous herbivorous. For clarity, only groups representing more than $1 \%$ of the total community are indicated in panel c.

Copepoda was the most abundant group, highly dominant in the WP2 both at seasonal and interannual scales. This group represented $87.8 \%$ of total density of the zooplankton collected by this net from 2004 to 2019 (Figure 2-c). The main temporal pattern in total zooplankton density was a sudden drop in 2015, mainly due to decline in Copepoda density. In opposition, Appendicularia increased at the same moment, but not enough to counterbalance the decrease of Copepoda. Phenological differences were observed among groups, with Copepoda more abundant in spring (March and April), whereas Appendicularia and Cladocera were more abundant in summer (between July and October, Figure 2-a). This was confirmed when looking more precisely at the monthly time series of the different groups, mostly classified in 2 categories: (i) those displaying high densities in spring until early summer, such as 
Copepoda, Salpida, Siphonophorae and Eumalacostraca, and (ii) those having high densities in summer and early autumn, such as Cladocera, Doliolida and gelatinous carnivorous with Chaetognatha and other Hydrozoa (ESM - Fig S3). As in previous analyses, no change in phenology (i.e., shift in the timing of the seasonal peak) was observed over the two decades.

In the Regent, Copepoda were also the most abundant group, but not as dominant (25.8\%). Gelatinous zooplankton as a whole accounted for higher percentage (50\%) than crustaceans (40\%, Figure 3-c). Total zooplankton slightly increased from 1995 to 2001 and then decreased until 2019. There were also strong year-to-year variations, such as peaks of Copepoda in 2006, Mollusca in 2000 or Salpida in 2013 (Figure 3-b). The peaks of zooplankton densities were observed in April, with Copepoda and Salpida, just followed by Hydrozoa in May and then Eumalacostraca from June to September and Chaetognatha from July to December (see also ESM-Fig S4). Here again, no shift in phenology was observed over the three decades. Due to the large mesh size of the net, some groups were poorly represented and even totally absent in the Regent net samples, such as Ostracoda and Cladocera (Figure 3; ESM-Fig S4).

The crustaceans' community in the Regent that could be investigated at the family level (see Material \& Methods) was well diversified with no strong dominance. Calanidae was the most abundant family, representing about $25 \%$ of total densities, followed by the other crustaceans $(22 \%)$. A decrease in total densities has been observed since 2002, but again with strong yearto-year fluctuations. In 2001, all the groups increased while Calanidae displayed a strong peak in 2006, which represented more than $60 \%$ of the total crustaceans community (Figure 4-b). Highest densities occurred between March and April, around $2.4 \log \left(\right.$ ind. $\left.m^{-3}+1\right)$, mainly with Calanidae (Figure 4-a). Eumalacostraca, which represent an important part of other crustaceans (see section 2.3), and Decapoda, were more abundant in late spring and summer. Metridinidae and Candacidae (each one representing around $10 \%$ of the community) were stable over time, with no seasonality and no interannual changes (Figure 4). Some taxa were however poorly represented, such as Penilia, Oithonidae, Oncaeidae and Acartiidae, and could therefore hardly be analyzed (see ESM-Fig S5). As for the other taxa, no shift in phenology was observed over the three decades (see ESM-Fig S5). 
a)

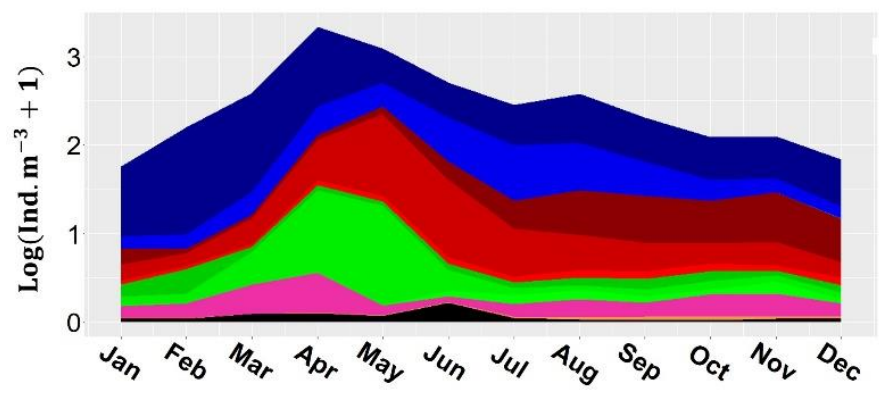

b)
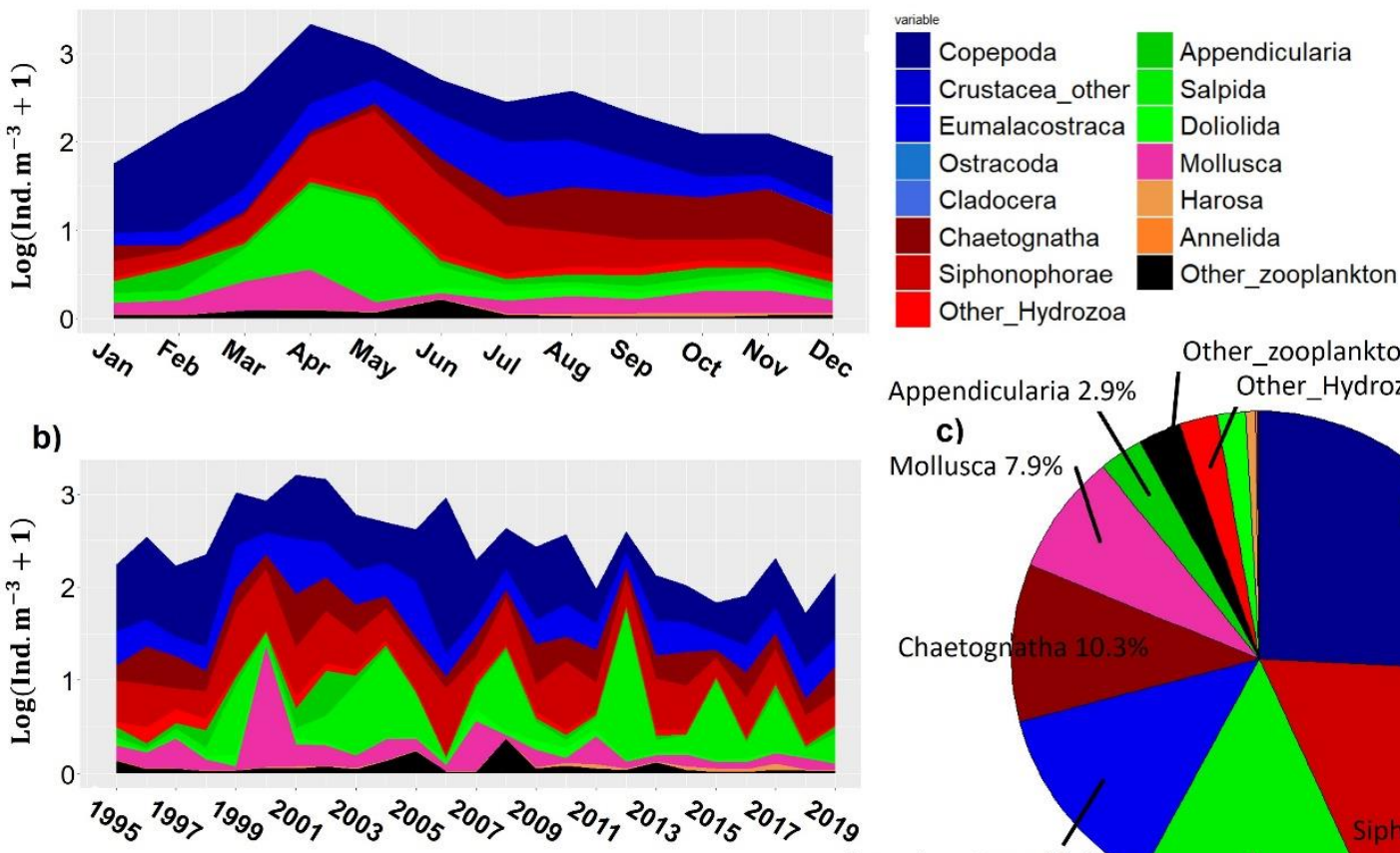

Other_Hydrozoa

Other_zooplankton $2.8 \%$

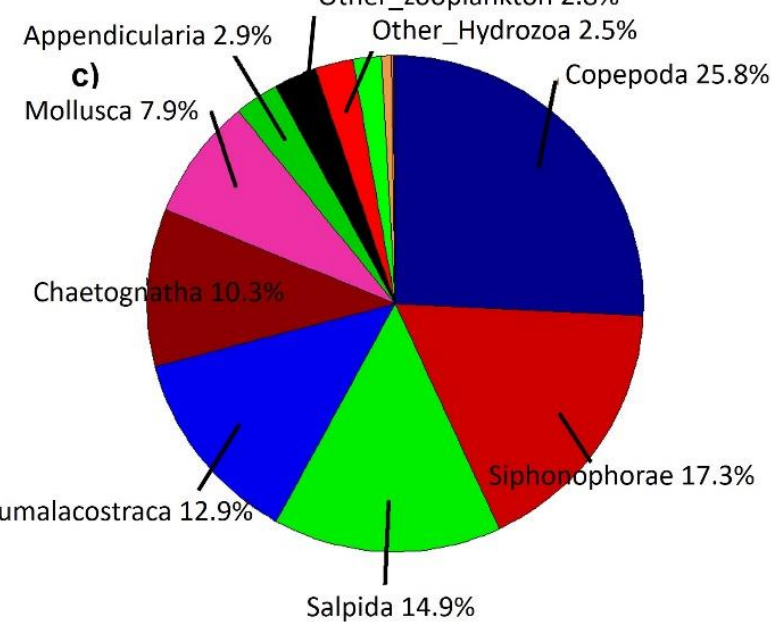

Figure 3: Stacked mean densities in the Regent net samples (for individuals over $1.5 \mathrm{~mm}$ body length) of each group for each month (a), stacked yearly densities of each group from 1995 to 2019 (b) and mean proportion of the different groups for the whole period (c). Blue colors represent the crustaceans, red colors the gelatinous carnivorous and green colors the gelatinous herbivorous.

a)

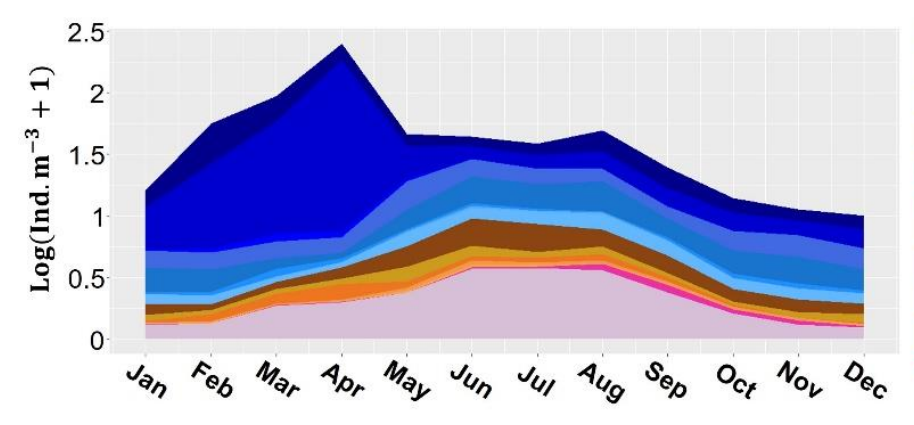

b)

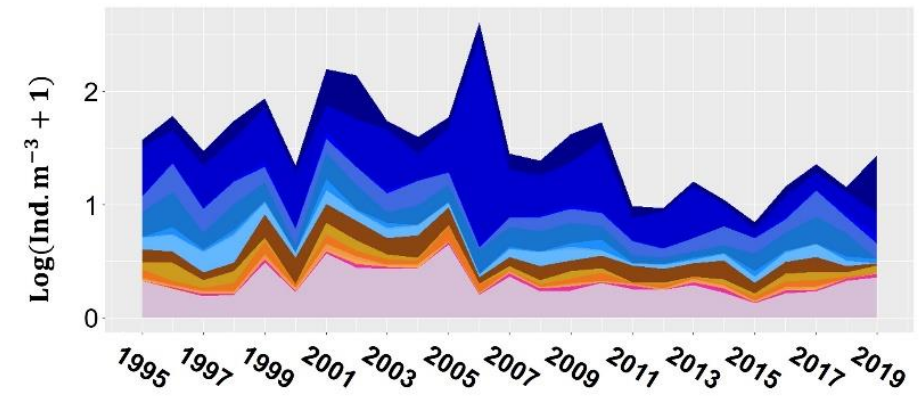

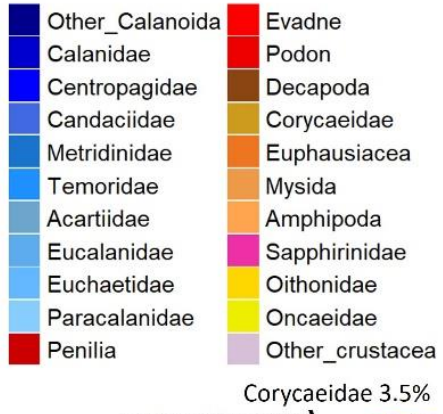

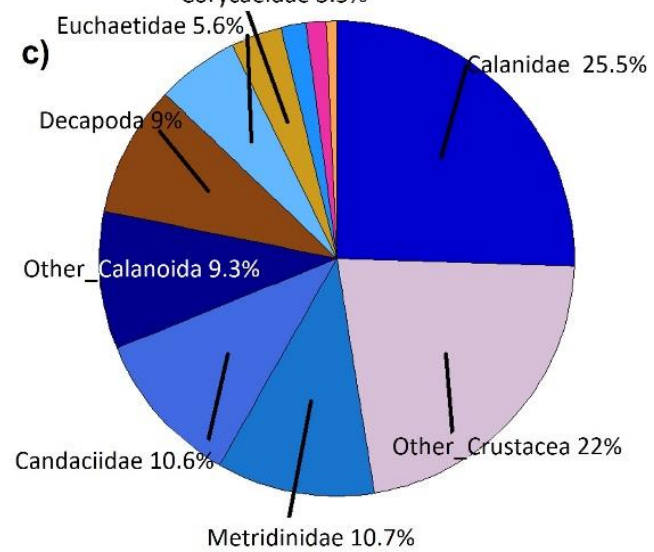


Figure 4: Stacked mean densities in the Regent net samples (for individuals over $1.5 \mathrm{~mm}$ body length) of each crustaceans' order, family and genera for each month (a), stacked yearly densities of each group from 1995 to 2019 (b) and mean proportion of the different groups for the whole period (c). Blue colors represent the Calanoida families, red colors the Cladocera and brown to orange colors the Eumalacostraca families.

\subsection{Crustaceans size spectra analysis}

The long-term trend of WP2 crustaceans NDSS slope (extracted by EVF) only accounted for $7 \%$ of the total variations of the series. The series of the NDSS slopes was quite stable from 2004 to 2014, with values at around -5.5. In 2015, the values of slopes increased (i.e. spectra became flatter) and remained at higher values around -5.2 afterwards. This change in 2015 was confirmed by the breakpoint analysis which detected a significant discontinuity in that year. Seasonal variations were also detected in that time series of NDSS slopes, with steeper spectra in spring and flatter spectra in summer and autumn (Figure 5a). This seasonality was confirmed by the wavelet analysis with high power values at around 12 months. However, this seasonality also disappeared in 2015 , when spectra became flatter all through the year (including spring, Figure 5a). As previously, no phenological change was observed, steeper spectra were always in spring between March and May.

Concerning the Regent, the long-term trend of crustaceans NDSS slope presented a higher percentage of the total variability of the series, at around 27\% (Figure 5b). The series was rather stable between 1995 and 2002 at values around -2.2 and then increased in 2003, with a breakpoint detected during that year, and spectra becoming flatter (mean slope of -1.8). The slopes of the spectra remained stable until 2010 and a second breakpoint was found in 2011 with spectra becoming even flatter (slope around -0.9). Finally, a last breakpoint was observed in 2016, when spectra became steeper, with mean slope at around -1.7 until 2019. No clear seasonal pattern was observed on the contour plot, but the wavelet showed high signal at around 12 months for some years, mainly between 2000 and 2005. Moreover, high frequencies ( 2 to 8 months) also presented strong signals indicating the presence of short-term variations or noise (Figure 5b). 

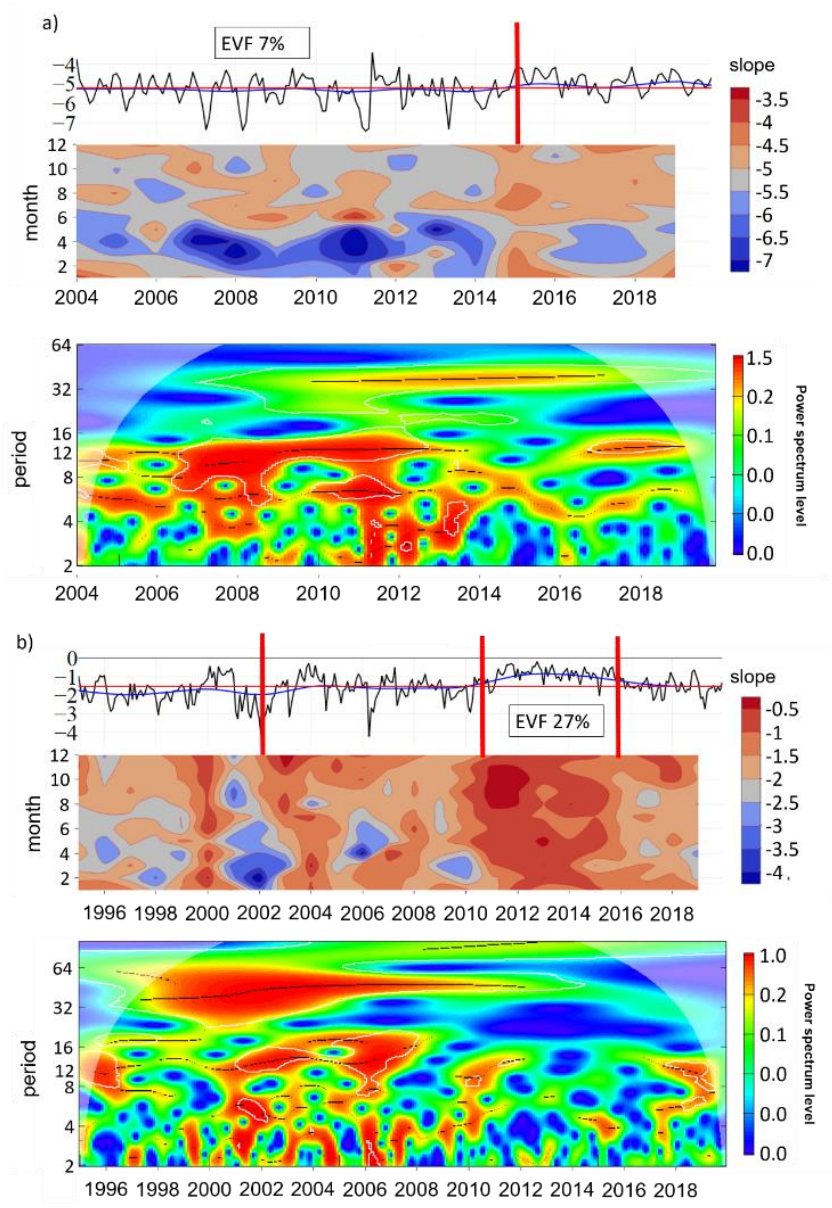

Figure 5: Monthly time series of crustaceans NDSS slopes from 2004 to 2019 in WP2 (a) and 424 Regent (b). The upper panel represents the monthly time series in black with a 3-year trend extracted with EVF (in blue) and the mean over the whole period (horizontal red line). The vertical red line indicates the position of the breakpoint detected. In the mid panel, the contour plot of the time series and in the bottom panel, wavelet analysis with significant variance delimited by white lines. 

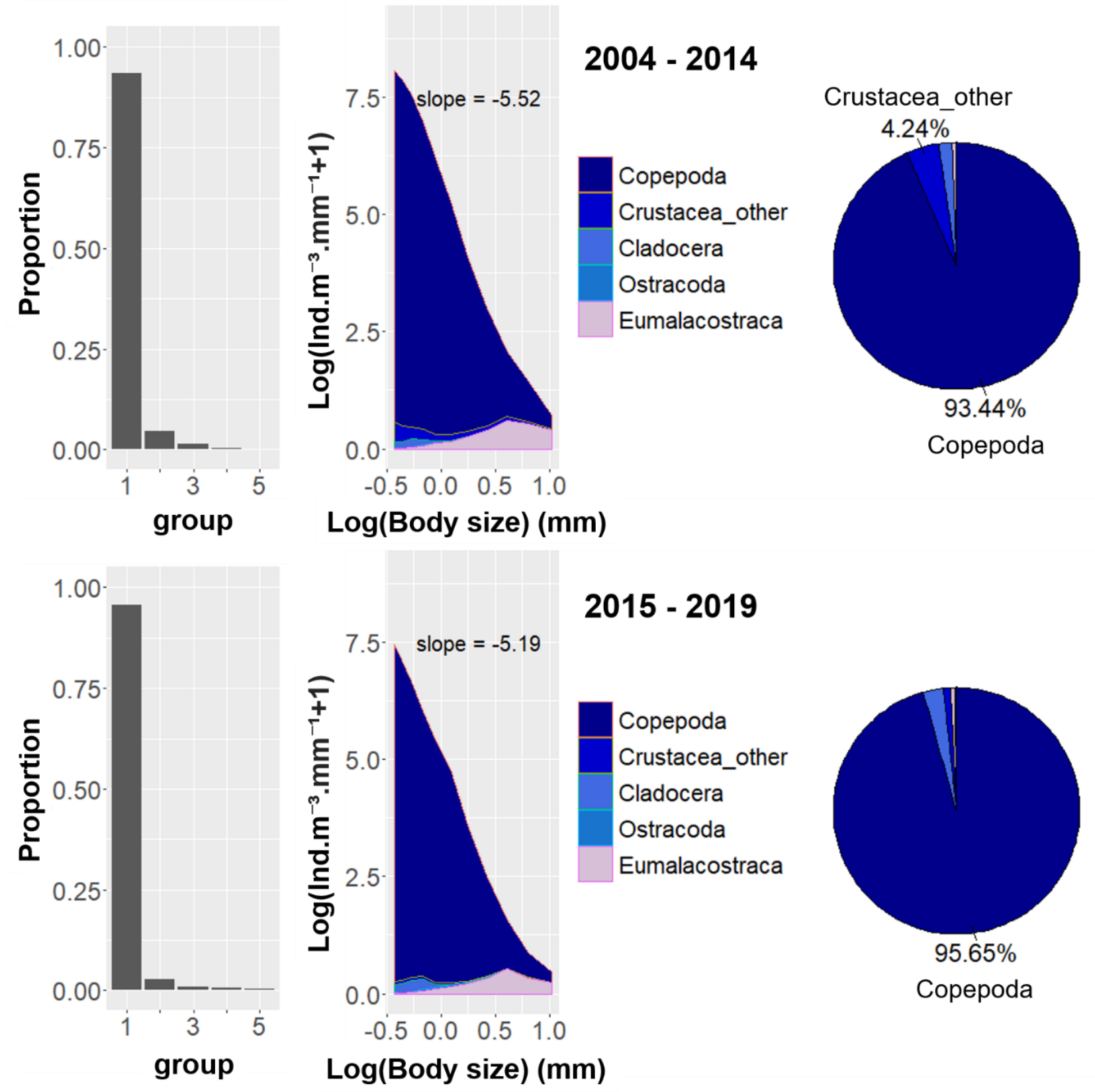

Figure 6: Rank-frequency diagram (left), mean NDSS size spectra (middle) and mean 431 proportions of crustaceans groups (right) for the 2 time periods identified with breakpoints 432 performed on monthly time series of crustaceans NDSS slopes in WP2. The slopes of the mean 433 spectra are indicated in each panel.

435 As already seen above, Copepoda was the most abundant group dominating the zooplanktonic 436 community in the WP2 and represented up to $95 \%$ of total densities of the crustaceans 437 between 2015 and 2019 (Figure 6). The first period between 2004 and 2014 presented steeper 438 size spectra with a mean slope of -5.5 compared to 2015-2019 period, for which mean slope 439 of spectra was around -5.2. The size spectra were thus steeper when the densities were higher. 
440 The rank frequency analyses presented only low variability between periods, the mean 441 proportion of the first group ranging from 0.94 to 0.96 (Figure 6).

442 In the Regent, Copepoda was also the most abundant group, representing between $60 \%$ and $44370 \%$ of the crustaceans densities while Eumalacostraca was the second group representing 444 between $26 \%$ and $36 \%$ of the crustaceans densities (Figure 7). The first period between 1995 445 and 2002 was characterized by the steepest spectra, with a mean slope of -2.2 and also the 446 highest densities (up to $2.1 \log \left(\right.$ densities. $\mathrm{mm}^{-1}$ )). In opposition, the third period between 2011 447 and 2015 displayed the flattest spectra, with mean slope of -0.91 and also the lowest densities $448\left(0.9 \log \left(\right.\right.$ densities. $\left.\left.\mathrm{mm}^{-1}\right)\right)$. Rank-frequency analysis showed few variations, the first group 449 representing between $59.1 \%$ and $69.2 \%$ of the community. Interestingly, the third period, 450 which was the less abundant, was also the less dominated by the first group (Figure 7).

451 The same analysis was also performed at a higher taxonomy level for the Regent. The 452 community was rather diversified, as indicated by the shape of the rank-frequency diagram 453 and the rather low percentage of first taxa ( $<30 \%$ for all periods). A high stability was 454 observed in the composition of the community with the same dominant taxa, i.e., other 455 crustaceans (Eumalacostraca) and Calanidae always the first 2 except in the last period 456 where other-Calanoida was in second position. The following most important groups were 457 Metridinidae, Candacidae, Corycaeidae and Decapoda, which represented between 6\% and $45811 \%$ of the community. No replacement of groups was observed except for Calanidae which 459 was partly replaced by other-Calanoida in the last period (Figure 8). Crustaceans community 460 appeared thus fairly stable and rather diversified, with no strong changes over time, despite 461 changes in the size spectra slopes. 

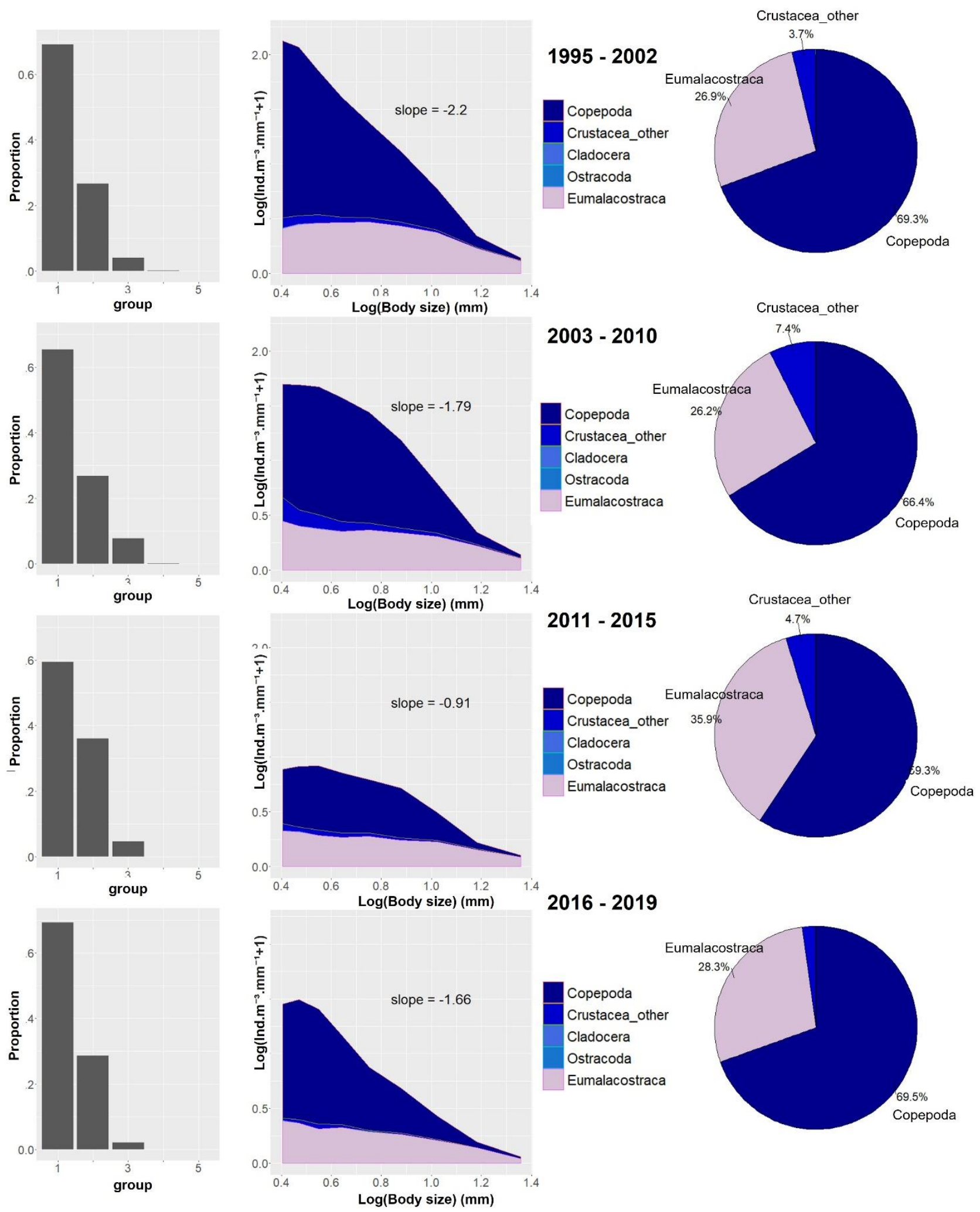

$2016-2019$

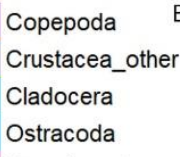

Eumalacostraca

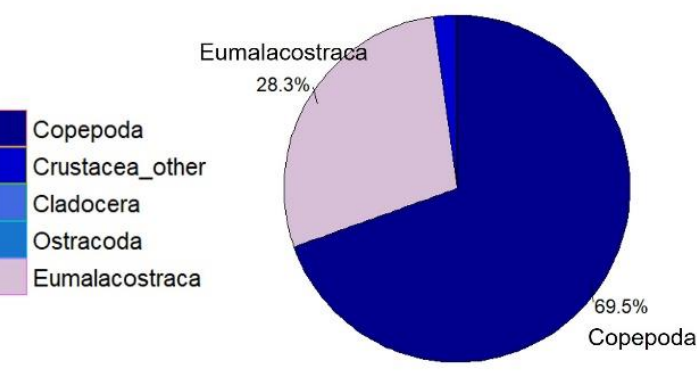

Figure 7: Rank-frequency diagram (left), mean NDSS size spectra (middle) and mean proportions of crustaceans groups (right) for the 4 time periods identified with breakpoints performed on monthly time series of crustaceans NDSS slopes in Regent net samples. The slopes of the mean spectra are indicated in each panel. 

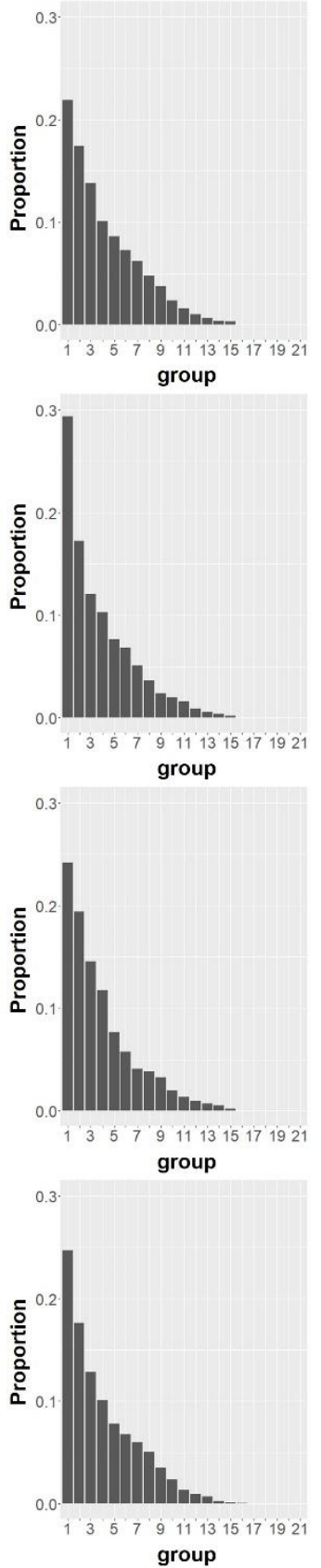

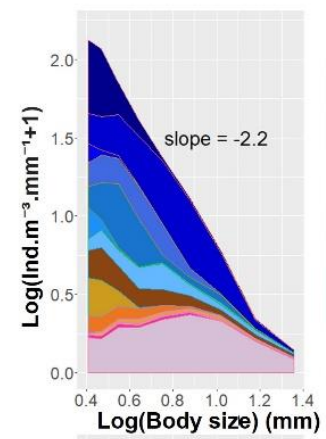

1995 - 2002
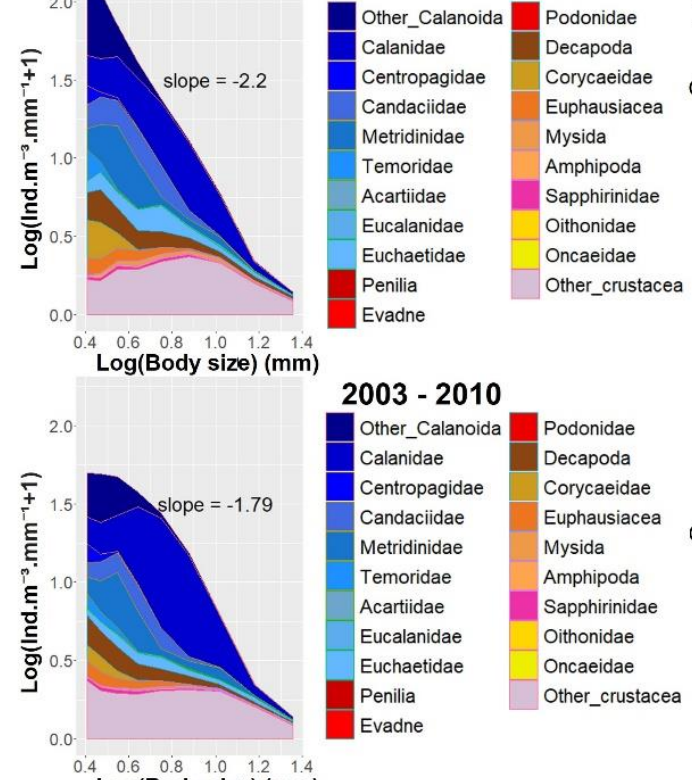

$2011-2015$

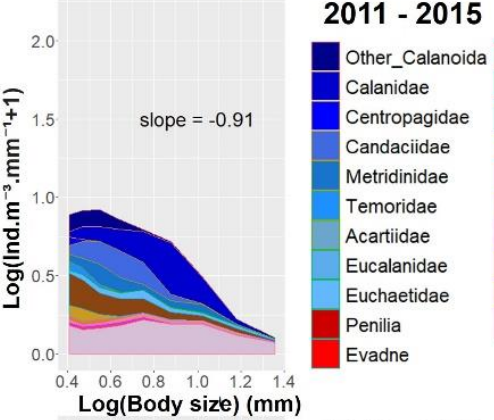

$2016-2019$

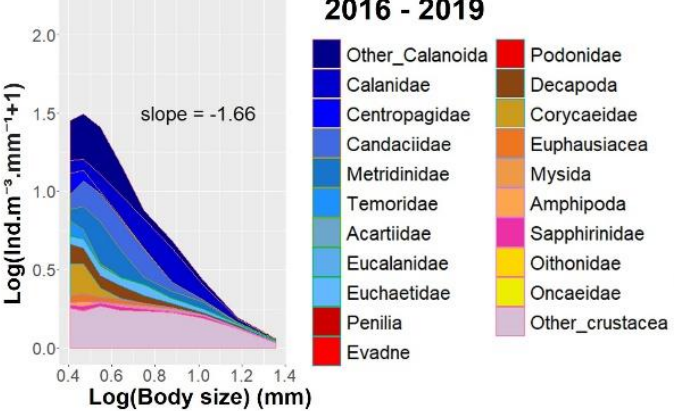

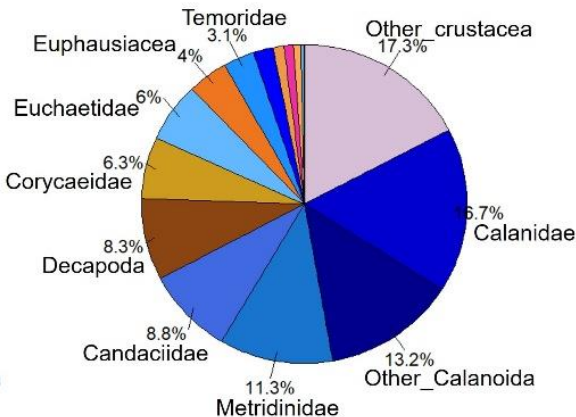
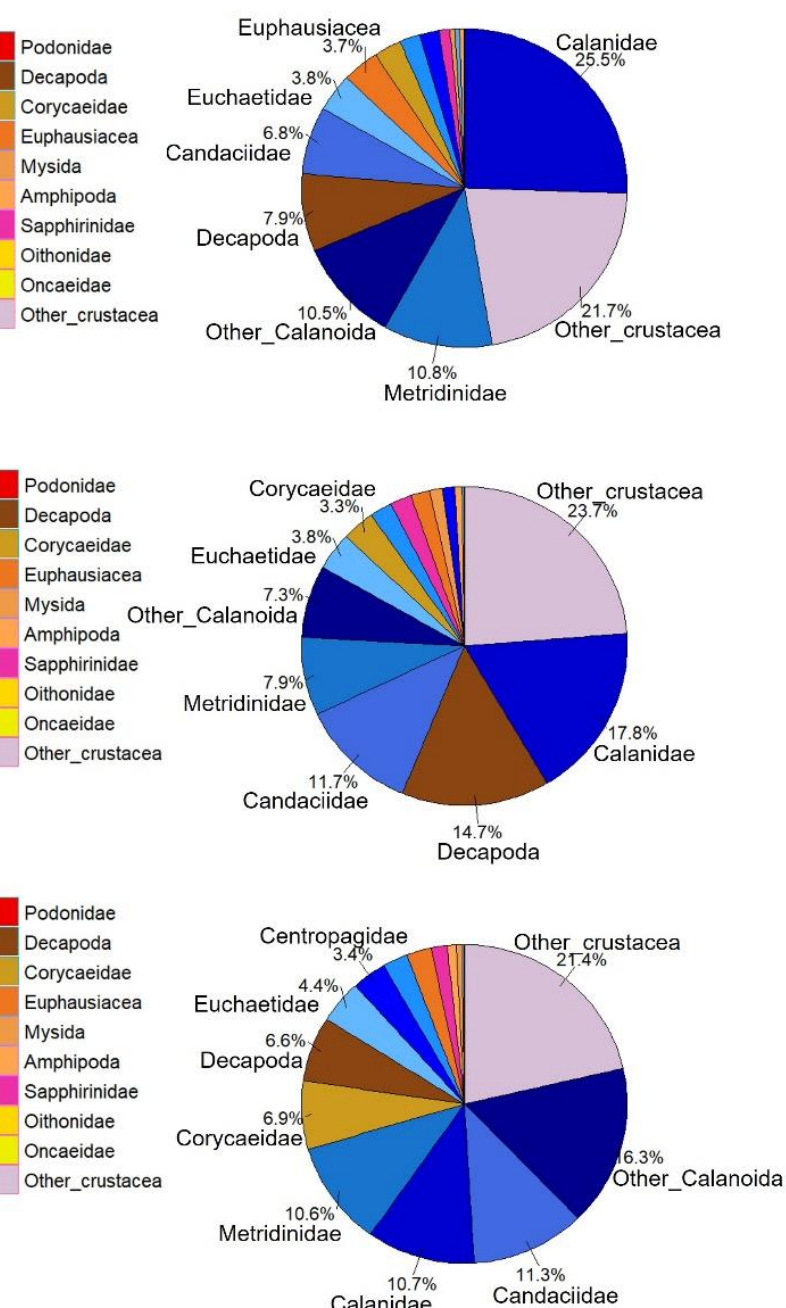

Figure 8: Rank-frequency diagram (left), mean NDSS size spectra (middle) and mean proportions of crustacean taxa (right) for the 4 time periods identified with breakpoints performed on $P C 1_{\text {size }}$ in Regent net. Calanoida are represented with blue colors, Cladocera in red and Eumalacostraca in brown to orange colors. The slopes of the mean spectra are indicated in each panel. In each pie chart, the percentage of Eumalacostraca in "Other_Crustacea" group is indicated in parentheses. 


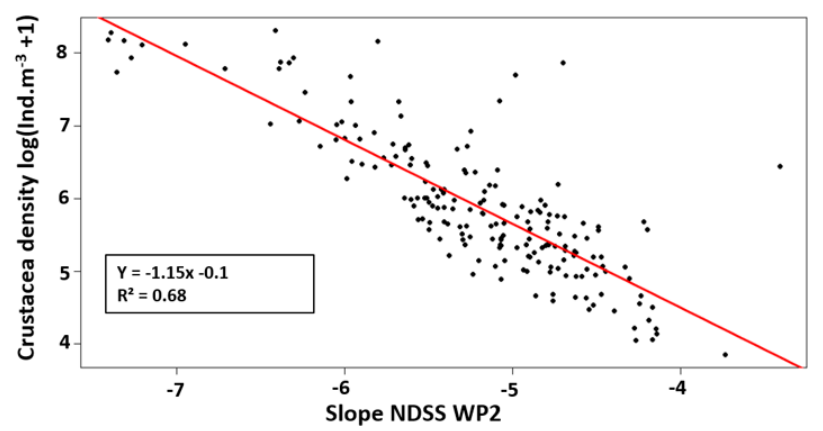

478

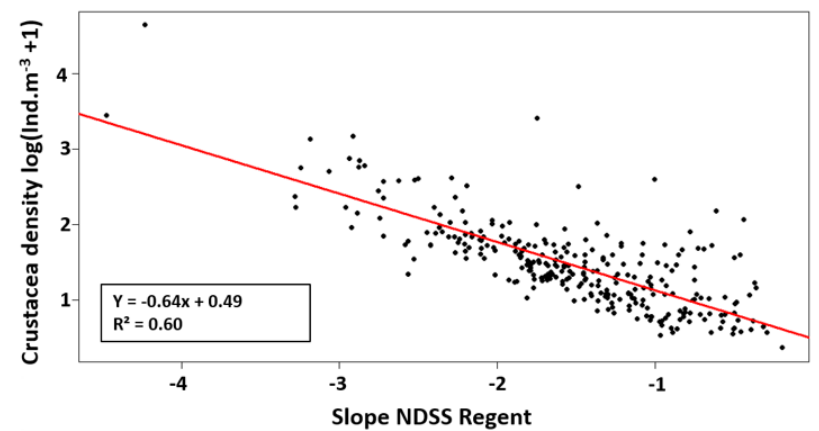

479 Figure 9: Linear regression between the monthly time series of crustaceans density and the slopes of monthly crustaceans NDSS for WP2 (top) and Regent (down).

482 As already suggested from Figures 6 and 7, there was a significant relationship between the monthly crustaceans total densities and the monthly slopes of the size spectra for both the 484 WP2 and Regent ( $<<0.001$, Figure 9). High densities of crustaceans were associated with steeper spectra and vice versa.

\subsection{Environmental and zooplankton variability}

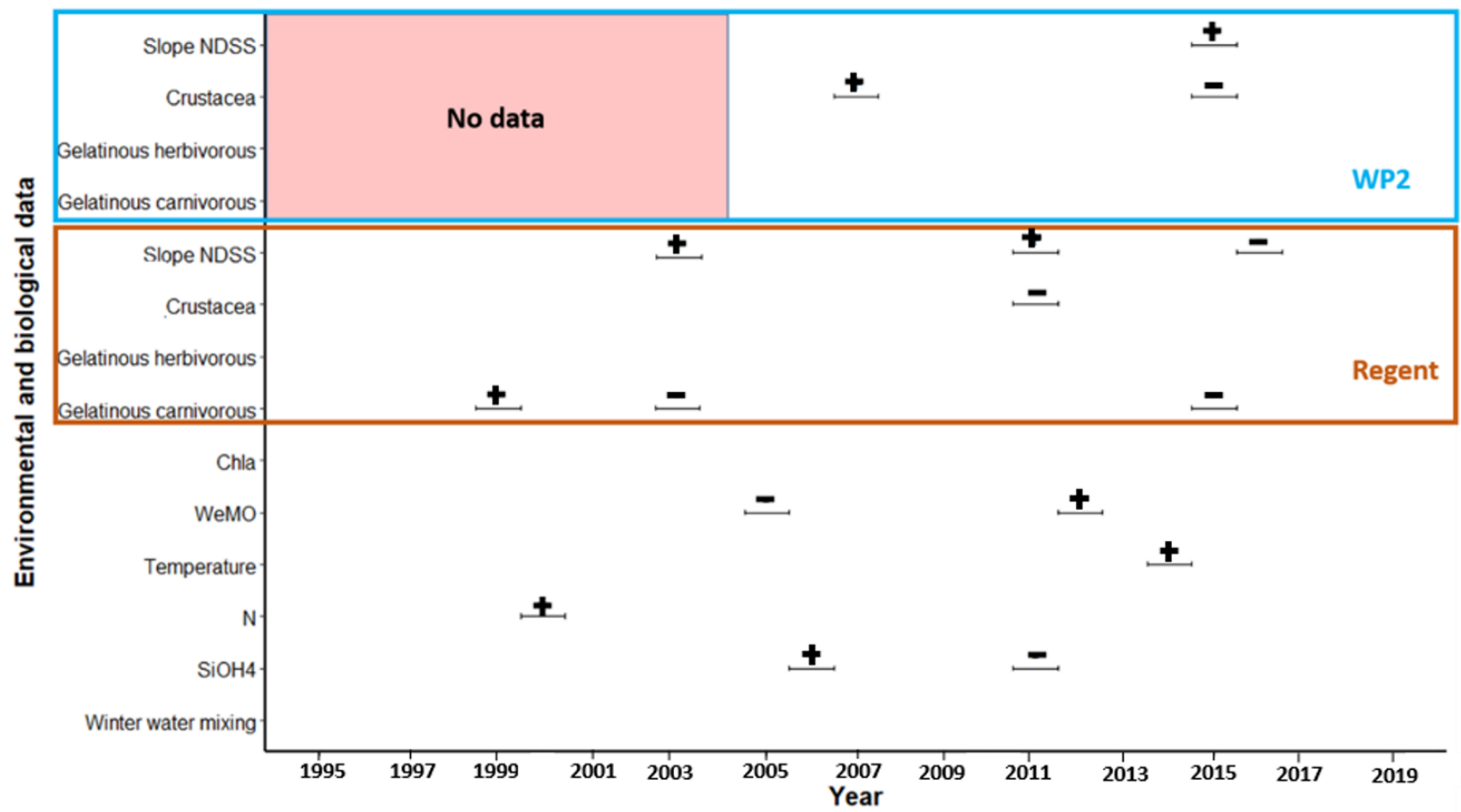


Figure 10: Synthesis of breakpoints detected in annual time series of crustaceans NDSS slopes, densities of crustaceans, gelatinous herbivorous and carnivorous and the environment. "+" indicate an increase of densities or environmental variables and spectra becoming flatter and inversely for "-", with a decrease of densities or environmental variables and spectra becoming steeper. Biological data in the WP2 are in the blue box and in the brown box for Regent.

494

Breakpoint analyses were also performed on annual time series of the environmental variables, i.e. Chl-a, WeMO, Temperature, N, SiOH4 and winter water mixing (see ESM FigS8 for annual time series) and no clear synchrony could be detected, as the breakpoints were observed at different dates for the different variables. Concerning the biological variables (crustacean size and density and gelatinous and herbivorous and carnivorous densities), several breakpoints were observed around 2015 when crustaceans decreased in the WP2 concomitant with a flattening of the crustaceans size spectra and a decrease of gelatinous carnivorous in the Regent (Figure 10). No clear link was made with the environment, albeit a sudden increase of temperature was observed a year before (in 2014). We further noted the co-occurrence of some breakpoints in crustaceans density and size spectra and $\mathrm{SiOH} 4$ concentration in 2011 (Figure 10). Before 2007, only changes in N and WeMO were observed in the environment with an increase of $\mathrm{N}$ and a decrease of WeMO. Carnivorous gelatinous also presented changes but not synchronous with $\mathrm{N}$ and WeMO.

\subsection{Relationship between crustaceans and environment}

510 To determine the potential environmental drivers of interannual variations in total crustaceans $511 \log$-density and size spectra, linear models were run considering 5 environmental explanatory variables: $\mathrm{N}$ and $\mathrm{SiOH} 4$ local concentrations, mean annual sea temperature, mean annual WeMO and the winter water mixing index. Chl-a was not incorporated in the complete model because of high level of Variance Inflation Factor (VIF>4) with the winter water mixing index, revealing collinearity between both variables. After model selection based on AICc, the best model retained for WP2 crustaceans log-densities was the one with mean annual temperature (but with a low probability level, $\mathrm{p}=0.091$, Table 1 ). This model only explained $19 \%$ of the amount of deviance. Residuals of the model were moderately satisfactory due to the presence of a few outliers, but the predicted versus observed values were reasonable (see ESM-Fig S10). Concerning the crustaceans density in the regent, only the winter water mixing was retained (at a higher probability level than the previous model, $\mathrm{p}=0.018$, Table 1 ), positively related to the crustaceans log-densities. This model nonetheless only explained 
524 the plot of the predicted versus observed values but here also 3 outliers were detected (see 525 ESM-Fig S10).

526 Regarding the size, no environmental variables were retained for the WP2 and only the 527 WeMO index was kept after selection for the Regent (but with a low probability level, $\mathrm{p}=$ 5280.118 , Table 1). It was negatively related to the time series of slopes, indicating that strong 529 values of WeMO could be related to steeper size spectra, but this model only explained $10.3 \%$ 530 of the amount of deviance. The residuals of the model were rather normally distributed 531 however the plot of the predicted versus observed values presented quite strong dispersion 532 (see ESM-Fig S10). 
534 Table 1: Statistics of the explanatory variables retained in the best model of crustaceans 535 densities and size in the WP2 and Regent nets. Variable with grey areas were not retained in 536 the best GLM model after variable selection

Crustacea WP2

\begin{tabular}{|c|c|c|c|c|c|c|c|c|c|c|c|c|}
\hline \multicolumn{5}{|c|}{ Crustacea WP2 } & \multicolumn{4}{|c|}{ Crustacea Regent } & \multicolumn{4}{|c|}{ NDSS slopes Regent } \\
\hline PARAMETER & Estimate & SE & $\mathbf{t}$ & $\mathbf{p}$ & Estimate & SE & $\mathbf{t}$ & $\mathbf{p}$ & Estimate & SE & $\mathbf{t}$ & $\mathbf{p}$ \\
\hline Intercept & 19.251 & 7.142 & 2.696 & 0.017 & 1.643 & 0.074 & 22.263 & $<0.001$ & -1.744 & 0.163 & -10.720 & $<0.001$ \\
\hline Temperature & -0.747 & 0.411 & -1.815 & 0.091 & & & & & & & & \\
\hline WeMO & & & & & & & & & -0.393 & 0.242 & -1.626 & 0.118 \\
\hline $\begin{array}{l}\text { Winter water } \\
\text { mixing }\end{array}$ & & & & & 0.128 & 0.050 & 2.552 & 0.018 & & & & \\
\hline
\end{tabular}

537

538

\section{4. Discussion}

540 The objective of this study was to investigate the main patterns of temporal variations of 541 zooplankton density, size spectra and taxonomic composition, with a focus on crustaceans, 542 weekly sampled at Point B at the entrance of the bay of Villefranche-sur-Mer (NW 543 Mediterranean Sea) from 1995 to 2019. If the density variability had already been studied 544 until early 2005 at this location (see García-Comas et al., 2011; Molinero et al., 2008a; 545 Vandromme et al., 2011), it was the first time that total density, size and community 546 composition were studied all together. Those 3 indicators are of primary importance to 547 understand trophic interactions, as size and community composition could modulate predator548 prey relationships and in the case of crustaceans also energy transfer to higher trophic levels 549 (Barroeta et al, 2017; Chen et al., 2019; Scharf et al., 2000). It was also the first time that such 550 a time series analysis was based on zooplankton samples simultaneously collected by 2 551 different nets, which allows us to cover a broader spectrum of the zooplankton community.

\section{Nets selectivity and individual's identification}

554 Like most zooplankton studies, this one relies on zooplanktonic individuals collected by nets 555 which are size selective (Mack et al., 2012; Pansera et al., 2014). To collect a large size range 556 of zooplankton, we used two nets with different mesh sizes: the WP2 and the Regent. The 557 WP2 has been widely used to study crustaceans and mostly copepods variability as 558 recommended by the UNESCO manual (Cook \& Hays, 2001; Raybaud et al., 2008; Tranter, 559 1968; Vandromme et al., 2014), while the Regent has been mostly used to sample gelatinous 560

organisms (Buecher \& Gibbons, 1999; Licandro et al., 2001). The Regent net has a larger 
561 mesh size than the WP2 $(690 \mu \mathrm{m}$ against $200 \mu \mathrm{m})$ and our analyses showed that 562 zooplanktonic organisms measuring at least $1.5 \mathrm{~mm}$ and $0.65 \mathrm{~mm}$ were accurately sampled by 563 the Regent and the WP2, respectively. Similar size threshold was estimated by Vandromme et 564 al., (2012) for the WP2, with a maximum of biovolume around $0.029 \mathrm{~mm}^{3}$ corresponding to 565 length (major axis) of around $650 \mu \mathrm{m}$. In the literature, the threshold between small and large 566 crustaceans is generally fixed at $1 \mathrm{~mm}$ (Hassel et al., 1991; Svensen et al., 2011; Wahlström et 567 al., 2000), so that WP2 analyses embraced both small and large crustaceans while the Regent 568 solely focused on large ones. So even if we covered a larger spectrum of zooplankton size 569 using samples from two nets than usually done, the variability of smaller individuals could 570 not be investigated with those nets. For instance, Microsetella, an important zooplankton 571 group of Mediterranean sea (Siokou-Frangou et al., 2010), was absent in both nets because of 572 its small size.

573 The Zooscan imaging methods used in this work has the advantage of measuring the size of 574 each individual providing consistent and repeatable results among samples, but it has a lower 575 taxonomic definition than traditional observations under microscopes (Gorsky et al., 2010). 576 Therefore in this study most zooplankton were sorted to the Order and sometimes to the 577 family when the morphological details were present, as done in many past studies on 578 zooplankton reported in Lombard et al., (2019).

579

\section{WP2 versus Regent}

581 The zooplanktonic community sampled by the WP2 was strongly dominated by copepods 582 ( $87 \%$ on average), while this sampled by the Regent was more diversified, with gelatinous in 583 general representing up to $50 \%$ of total zooplankton in the net. Still, when comparing zooplankton densities in both nets considering individuals greater than $1500 \mu \mathrm{m}$, the Regent underestimated the densities of all the groups (including gelatinous ones) compared to the WP2. This result was unexpected, especially for the gelatinous, as Regent net is supposed to be more performing and less damaging for those groups (Buecher \& Gibbons, 1999). The WP2 net appeared to be a better choice to sample the zooplankton community at the broad taxonomic level at the point B of Villefranche-sur-mer, both for crustaceans and gelatinous taxa.

591 Because size spectra were normalised, the slopes of NDSS in both nets could be compared considering different size range of individuals. Crustacean NDSS in the WP2 appeared steeper than in the Regent net, revealing a higher proportion of small individuals compared to larger ones in the WP2. NDSS in the WP2 was however less variable, possibly because of a 
595 higher number of individuals considered to construct size spectra compared to Regent. NDSS

596 differed also in term of variability with different breakpoints identified in the time series of 597 both nets. For instance, high proportions of large individuals (inducing a flatter size spectrum) 598 were observed from 2016 to 2019 and 2011 to 2014 for the WP2 and the Regent, respectively. 599 Those differences could be explained by the differences in the proportion of the different taxa 600 sampled by each net. Indeed, Eumalacostraca (among the largest crustaceans) represented 601 one third of the community in the Regent, but less than $1 \%$ in the WP2. Conversely, 602 Cladocera, such as Penilia, Podonidae or Evadne (of relatively small size) were present in the 603 WP2, but absent in the Regent net. Such differences between two nets are not so surprising 604 and Calbet et al., (2001) also observed strong differences in the zooplankton community 605 sampled by nets of $53 \mu \mathrm{m}$ and $200 \mu \mathrm{m}$ mesh size at the same time.

606 Nevertheless, the identification of individuals at the family level for crustaceans in the Regent 607 provided useful additional information (see below) that was not available for the WP2 608 because of the difficulty to precisely and rapidly identify small individuals on automatically609 generated images. However, even in the Regent, the identification of individuals at the family level was only available for copepods and not for the other groups partly limiting our vision of the community variability. It appears then crucial to develop higher resolution sensor and new process to semi-automatically identify at the species level smaller crustaceans individuals sampled by the WP2, and more generally zooplankton net samples, to better understand the links with the environment and interactions with upper trophic levels.

\section{Temporal stability of the zooplankton community}

617 One of the most striking results of this analysis is the strong stability through time of the zooplankton community (in both the WP2 and Regent) and when zooplankton total densities varied, the taxa varied most often synchronously. The examination of the crustaceans community at a higher taxonomic resolution in the Regent led to the same conclusion of a high stability and diversity in the taxonomic composition (with similar proportions of

622 Calanidae, other-Calanoida, Metridinidae, Candacidae Corycaeidae and Decapoda through time). Similarly, the crustaceans and gelatinous densities as well as size spectra slope of crustaceans presented strong long-term stability, as documented by the low percentage of variance explained by the long-term trend. Some interannual variability was observed in zooplankton size, as depicted by the flattening of spectra in the WP2 in the last years suggesting an increase of the proportion of larger individuals. However, this flattening was not induced by an increase in the density of larger individuals but rather by a reduction of 
smaller individuals, potentially leading to lower energy transfer to higher trophic levels. Different changes of slopes were also observed in the Regent but the only notable variation was the decrease in crustaceans densities in the last years. Such stability and high resilience in the zooplankton community was unexpected, especially in a context of global warming of the Mediterranean waters, but this has been also reported in several other Mediterranean locations (see Berline et al., 2012; Fullgrabe et al., 2020; Mazzocchi et al., 2011; 2012).

\section{Zooplankton long-term variability and global warming}

This strong stability of the community could be surprising in a context of global change and long-term changes in phytoplankton and zooplankton phenology or size have been already observed in several areas and related to increasing temperature (Aberle et al., 2012; Herrmann et al., 2014; Winder et al., 2012). Our study did not display any clear relationships between environmental and planktonic variables, albeit a negative (but statistically fragile) relationship between crustaceans density in the WP2 and annual temperature. Such a relationship between crustaceans densities and temperature had been documented in some studies in the Mediterranean sea (Fernández De Puelles \& Molinero, 2008a; Fernández de Puelles et al., 2004). No link was observed between the crustaceans size spectra and the temperature in this study, as in other studies (Dziuba et al., 2017; García-Comas et al., 2014). Concerning the gelatinous community, a usual expectation from the global warming is the increase in gelatinous densities, with potential impact on copepods through competition and/or predation (Molinero et al., 2008a). Warm temperatures are indeed thought to promote an increase of asexual reproduction of hydrozoans and, consecutively, an increase of gelatinous species (Purcell, 2005). However, our results do not support this hypothesis, as herbivorous and carnivorous gelatinous densities were rather stable through time (as crustaceans) and further did not display any positive relationship with temperature. However, disentangling long-term trend from interannual variability with 25 years long time series is not an easy task and longer time series are probably needed to reach more robust conclusion on this issue.

\section{Zooplankton interannual variability and winter conditions}

Previous studies in the Ligurian sea highlighted the importance of interannual variability rather than monotonous long-term change in the zooplankton community (García-Comas et al., 2011; Molinero et al., 2005; Vandromme et al., 2011) and pointed out the importance of winter conditions. The impacts of winter conditions on phytoplanktonic and zooplanktonic production was shown by Fullgrabe et al., (2020) and Goffart et al., (2015) in the Ligurian sea 
663

664

665

666

667

668

669

670

671

672

673

674

675

676

677

678

679

680

681

682

683

684

685

686

687

688

689

690

691

692

693

694

695

and to a lesser extent by Mazzocchi et al., (2011) in the Thyrrenian sea. In the Ligurian sea, quasi-decadal climatic fluctuation, associated to the NAO, was proposed as the driving changes for winter mixing intensity and the input of nutrient at the surface (Molinero et al., 2008a; Garcia-Comas et al., 2011; Fullgrabe et al., 2020). According to those authors, strong winter mixing (such as in the 80s and from 1999 to 2003) would lead to an increase of nutrient input at the surface and a subsequent higher primary and secondary production in spring. While interannual variability was detected in the zooplankton time series (e.g. decrease in crustacean density after 2015 or changes in size spectra slopes in the Regent in 2003, 2011 and 2016), our study did not detect any strong relationship between the crustaceans densities or size spectra and winter mixing (and environmental variables). The dates of the breakpoints between the environmental and biological variables were furthermore not synchronous while the percentages of variance explained by the different linear models did not exceed $22 \%$. The relationship between crustaceans density in the Regent and winter water mixing would be the sole result supporting the hypothesis of an impact of winter mixing on zooplankton production, (as raised by Garcia-Comas et al., 2011 and Vandromme et al., 2011). It was however not the case for crustaceans in the WP2, which however better samples the crustaceans than the Regent (see above), but which time series was only 16 years long (probably too short to reflect quasi-decadal variations found by the previous studies).

\section{Zooplankton seasonal variability}

Both crustaceans size and density presented a clear seasonal cycle in the WP2. This pattern is well documented in the literature, resulting from the phyto- and zooplankton production coupling (Romagnan et al., 2015,2016; Rossi \& Jamet, 2009). The development of zooplankton populations follows the spring phytoplankton bloom, with successive development of grazers and carnivorous predators (Sommer et al., 1986). For copepods, recruitment of copepodites occurs mainly in spring, but can be modulated by environmental conditions (Romagnan et al., 2016). This recruitment pattern explained, in the WP2, the presence of higher densities and steeper size spectra in spring for crustaceans, which has probably participated to the strong negative relationship between size spectra slope and densities. This seasonal signal was however less marked for gelatinous in the WP2 and absent in the Regent for both for crustaceans and gelatinous. We postulate that this lack of seasonal pattern in the Regent was due to its large mesh size that prevents catching the small size classes, such as the copepodites that mostly appear in spring during the phytoplankton bloom 
696 (Romagnan et al., 2015). No phenological shift was observed in the timing of crustaceans 697 peak, but the seasonal signal totally disappeared since 2015.

698

\section{The 2015 event}

700

701

702

703

704

705

706

707

708

709

710

711

712

713

714

715

716

717

718

719

720

721

722

723

724

725

726

727

728

729

Another important result of this study was the identification of the 2015 event, characterised in the WP2 by a sudden and significant drop in crustaceans densities (concomitant to a loss of the seasonal signal) as well as those of the gelatinous taxa (but to a lesser extent). This decrease in the crustaceans (mostly copepods of small size) also led to changes in the size spectra (being flatter). Low densities of crustaceans have been also recorded in 2015 in other areas of the NW Mediterranean sea, such as in the Bay of Calvi and the Alboran sea (Fullgrabe et al., 2020; García-Martínez et al., 2019). This event could be related to the sudden warming in 2015 at the point B station (being the hottest year of the time series), but also more generally in the NW Mediterranean Sea (Margirier et al., 2020). Such an hypothesis needs however to be validated by further work and longer time series, as it is currently supported by only one occurrence. Furthermore, the planktonic dynamics may be more complex than a simple relationship between winter mixing, nutrient concentration (albeit these two variables might be important), as described by the critical depth hypothesis (Sverdrup 1953). Behrenfeld, (2010) indeed stressed the key role of biotic interactions within and between the phytoplanktonic and zooplanktonic communities, especially the balance between phytoplankton growth and grazing in the bloom dynamics. Preliminary analyses on Chl- $a$ pigment concentration at point $\mathrm{B}$ station suggested a decrease in diatom proportion since 2013, more pronounced in 2015, and an increase in dinoflagellates (Maria Luiza Pedrotti pers.comm). Such changes in the phytoplankton community composition could negatively impact crustaceans and favour appendicularians, which feed on smaller preys (Katechakis et al, 2004; Sommer, et al., 2002a; Sommer et al, 2002b). Competition within or between zooplanktonic groups may thus be an additional key element of their dynamics and need to be deeper investigated.

\section{Crustaceans and gelatinous interactions}

Top down control of jellyfish on copepods (i.e. predation) has been proposed by Molinero et al. $(2005,2008 \mathrm{~b})$ based on time series analyses at the same site, as the densities of the later dropped during the late $80 \mathrm{~s}$ and early $90 \mathrm{~s}$ when the former increased. However, using the same time series with 10 more years, Garcia-Comas et al. (2011) found that total copepods recovered around 2003 densities similar as those of the 80s, while jellyfish remained 
abundant. In this study, we considered two main groups of gelatinous, the carnivorous and the herbivorous (filter-feeders), as they have different interactions with crustaceans (especially copepods), by predation or competition with the first and second gelatinous group, respectively (Molinero et al., 2008b). Densities of crustaceans and carnivorous gelatinous were highly positively correlated in both the WP2 and Regent (see ESM Fig-S9), which does not support the hypothesis of a top-down control of gelatinous on crustaceans through predation. Weak positive covariations between densities of crustaceans and gelatinous herbivorous in both nets also did not support the potential hypothesis of competition between the two groups. The gelatinous herbivory densities did not display any trend and remained rather stable, even during the crustaceans drop around 2015. Overall, the present work did not support the hypothesis of a top-down control of gelatinous on the crustaceans at the point B.

\section{Zooplankton and small pelagic fish}

Through this study, we wanted to explore the main patterns of zooplankton variations at the point $\mathrm{B}$, with a focus on crustaceans, to investigate if any major changes occurred around 2007, when the small pelagic fish community from an adjacent area (the Gulf of Lions) displayed a major regime shift (Saraux et al. 2019). Such bottom-up processes have been already documented (Brosset et al., 2016; Espinoza et al., 2009; Van der Lingen et al., 2006) or strongly suspected (Véron et al., 2020). However, zooplankton data availability is often too limiting to fully investigate potential relationships between plankton and fish. As the rare long-term plankton time series available in the NW Mediterranean tended to indicate synchronous variations at large spatial scale, possibly associated with large or regional oceanatmosphere oscillations (Brosset et al., 2017; Fullgrabe et al., 2020; Vandromme et al., 2011), it was of interest to explore the long time series of the point B. The present study did not detect any specific changes in the zooplanktonic community around 2007 that would support this bottom-up control hypothesis. It remains however unclear if this indeed results from the absence of bottom-up control on the small pelagic fish or if this results from different dynamics in the plankton communities of those two areas (a preliminary analysis indicating that the zooplankton taxonomic compositions differ between the Gulf of Lions and the Ligurian Sea, (Feuilloley, 2020)). We finally think that a thorough understanding of the impacts of climate change on the functioning of an ecosystem requires simultaneous observations of its different biotic and abiotic compartments (Doray et al., 2018), as this is recommended by the ecosystemic approach to fisheries (FAO 2003). 
Data availability

766

767

768

769

770

771

772

773

774

775

776

777

778

779

780

781

782

783

784

785

786

787

788

789

790

791

792

793

794

795

796

797

The data underlying this article will be shared on reasonable request to the corresponding author.

\section{Bibliography}

Aberle, N., Bauer, B., Lewandowska, A., Gaedke, U., \& Sommer, U. (2012). Warming induces shifts in microzooplankton phenology and reduces time-lags between phytoplankton and protozoan production. Marine Biology, 159(11), 2441-2453. https://doi.org/10.1007/s00227-012-1947-0

Acuña, J. L. (2001). Pelagic tunicates: why gelatinous? The American Naturalist, 158(1), $100-107$.

Auger, P. A., Ulses, C., Estournel, C., Stemmann, L., Somot, S., \& Diaz, F. (2014). Interannual control of plankton communities by deep winter mixing and prey/predator interactions in the NW Mediterranean: Results from a 30-year 3D modeling study. Progress in Oceanography. https://doi.org/10.1016/j.pocean.2014.04.004

Barroeta, Z., Olivar, M. P., \& Palomera, I. (2017). Energy density of zooplankton and fish larvae in the southern Catalan Sea (NW Mediterranean). Journal of Sea Research. https://doi.org/10.1016/j.seares.2017.04.008

Beaugrand, G., \& Kirby, R. R. (2010). Climate, plankton and cod. Global Change Biology, 16(4), 1268-1280.

Behrenfeld, M. J. (2010). Abandoning Sverdrup's critical depth hypothesis on phytoplankton blooms. Ecology, 91(4), 977-989.

Berline, L., Siokou-Frangou, I., Marasović, I., Vidjak, O., de Puelles, M. L. F., Mazzocchi, M. G., ... Conversi, A. (2012). Intercomparison of six Mediterranean zooplankton time series. Progress in Oceanography, 97, 76-91.

Bopp, L., Resplandy, L., Orr, J. C., Doney, S. C., Dunne, J. P., Gehlen, M., ... Seferian, R. (2013). Multiple stressors of ocean ecosystems in the 21st century: projections with CMIP5 models. Biogeosciences, 10, 6225-6245.

Brosset, P, Le Bourg, B., Costalago, D., BǍnaru, D., Van Beveren, E., Bourdeix, J. ., ... Saraux, C. (2016). Linking small pelagic dietary shifts with ecosystem changes in the Gulf of Lions. Marine Ecology Progress Series. https://doi.org/10.3354/meps11796

Brosset, Pablo, Fromentin, J.-M., Van Beveren, E., Lloret, J., Marques, V., Basilone, G., ... 
Saraux, C. (2017). Spatio-temporal patterns and environmental controls of small pelagic fish body condition from contrasted Mediterranean areas. Progress in Oceanography. https://doi.org/10.1016/j.pocean.2016.12.002

Buecher, E., \& Gibbons, M. J. (1999). Temporal persistence in the vertical structure of the assemblage of planktonic medusae in the NW Mediterranean Sea. Marine Ecology Progress Series, 189, 105-115.

Burnham, K. P., \& Anderson, D. R. (2004). Multimodel inference: understanding AIC and BIC in model selection. Sociological Methods \& Research, 33(2), 261-304.

Calbet, A., Garrido, S., Saiz, E., Alcaraz, M., \& Duarte, C. M. (2001). Annual zooplankton succession in coastal NW Mediterranean waters: the importance of the smaller size fractions. Journal of Plankton Research, 23(3), 319-331.

Carey, C. C., Hanson, P. C., Lathrop, R. C., \& St. Amand, A. L. (2016). Using wavelet analyses to examine variability in phytoplankton seasonal succession and annual periodicity. Journal of Plankton Research, 38(1), 27-40.

Chatfield, C. (2003). The analysis of time series: an introduction. Chapman and Hall/CRC.

Chen, C.-T., Bănaru, D., Carlotti, F., Faucheux, M., \& Harmelin-Vivien, M. (2019). Seasonal variation in biochemical and energy content of size-fractionated zooplankton in the Bay of Marseille (North-Western Mediterranean Sea). Journal of Marine Systems, 199, 103223.

Cook, K. B., \& Hays, G. C. (2001). Comparison of the epipelagic zooplankton samples from a U-Tow and the traditional WP2 net. Journal of Plankton Research, 23(9), 953-962.

Curran-Everett, D. (2018). Explorations in statistics: the log transformation. Advances in Physiology Education, 42(2), 343-347.

Cury, P., Bakun, A., Crawford, R. J. M., Jarre, A., Quinones, R. A., Shannon, L. J., \& Verheye, H. M. (2000). Small pelagics in upwelling systems: patterns of interaction and structural changes in "wasp-waist” ecosystems. ICES Journal of Marine Science, 57(3), $603-618$.

Cushing, D. H. (1990). Plankton production and year-class strength in fish populations: an update of the match/mismatch hypothesis. In Advances in marine biology (Vol. 26, pp. 249-293). Elsevier.

Dallot, S., Goy, J., \& Carre, C. (1988). Peuplements de carnivores planctoniques gélatineux et structures productives en Méditerranée occidentale. Oceanologica Acta, Special Issue.

Daufresne, M., Lengfellner, K., \& Sommer, U. (2009). Global warming benefits the small in aquatic ecosystems. Proceedings of the National Academy of Sciences, 106(31), 12788- 
12793.

833

834

835

836

837

838

839

840

841

842

843

844

845

846

847

848

849

850

851

852

853

854

855

856

857

858

859

860

861

862

863

864

865

Doray, M., Petitgas, P., Romagnan, J. B., Huret, M., Duhamel, E., Dupuy, C., ... Berger, L. (2018). The PELGAS survey: ship-based integrated monitoring of the Bay of Biscay pelagic ecosystem. Progress in Oceanography, 166, 15-29.

Dziuba, M. K., Cerbin, S., \& Wejnerowski, L. (2017). Is bigger better? A possibility for adaptation of Daphnia to filamentous cyanobacteria in the face of global warming. Hydrobiologia, 798(1), 105-118.

Espinoza, P., Bertrand, A., van der Lingen, C. D., Garrido, S., \& de Mendiola, B. R. (2009). Diet of sardine (Sardinops sagax) in the northern Humboldt Current system and comparison with the diets of clupeoids in this and other eastern boundary upwelling systems. Progress in Oceanography, 83(1-4), 242-250.

Fernández De Puelles, M. L., \& Molinero, J. C. (2008). Decadal changes in hydrographic and ecological time-series in the Balearic Sea (western Mediterranean), identifying links between climate and zooplankton. In ICES Journal of Marine Science. https://doi.org/10.1093/icesjms/fsn017

Fernández de Puelles, M. L., Valencia, J., \& Vicente, L. (2004). Zooplankton variability and climatic anomalies from 1994 to 2001 in the Balearic Sea (Western Mediterranean). ICES Journal of Marine Science, 61(4), 492-500.

Feuilloley, G. (2020). Analyse de la variabilité spatio-temporelle du zooplancton dans le Golfe du Lion et conséquences sur les populations de petits pélagiques.

Fullgrabe, L., Grosjean, P., Gobert, S., Lejeune, P., Leduc, M., Engels, G., ... Richir, J. (2020). Zooplankton dynamics in a changing environment: A 13-year survey in the northwestern Mediterranean Sea. Marine Environmental Research, 104962.

García-Comas, C., Chang, C.-Y., Ye, L., Sastri, A. R., Lee, Y.-C., Gong, G.-C., \& Hsieh, C. (2014). Mesozooplankton size structure in response to environmental conditions in the East China Sea: How much does size spectra theory fit empirical data of a dynamic coastal area? Progress in Oceanography, 121, 141-157.

García-Comas, C., Stemmann, L., Ibanez, F., Berline, L., Mazzocchi, M. G., Gasparini, S., ... Gorsky, G. (2011). Zooplankton long-term changes in the NW Mediterranean Sea: Decadal periodicity forced by winter hydrographic conditions related to large-scale atmospheric changes? Journal of Marine Systems. https://doi.org/10.1016/j.jmarsys.2011.04.003

García-Martínez, M. del C., Vargas-Yáñez, M., Moya, F., Santiago, R., Reul, A., Muñoz, M., ... Balbín, R. (2019). Spatial and Temporal Long-Term Patterns of Phyto and 

Zooplankton in the W-Mediterranean: RADMED Project. Water, 11(3), 534.

Goffart, A., Hecq, J.-H., \& Legendre, L. (2015). Drivers of the winter-spring phytoplankton bloom in a pristine NW Mediterranean site, the Bay of Calvi (Corsica): A long-term study (1979-2011). Progress in Oceanography, 137, 121-139.

Gorsky, G., Ohman, M. D., Picheral, M., Gasparini, S., Stemmann, L., Romagnan, J.-B., ... Prejger, F. (2010). Digital zooplankton image analysis using the ZooScan integrated system. Journal of Plankton Research, 32(3), 285-303.

Grosjean, P., Ibanez, F., \& Etienne, M. (2014). Pastecs: Package for analysis of space-time ecological series. $R$ Package Version, $1,1-3$.

Hassel, A., Skjoldal, H. R., Gjøsæter, H., Loeng, H., \& Omli, L. (1991). Impact of grazing from capelin (Mallotus villosus) on zooplankton: a case study in the northern Barents Sea in August 1985. Polar Research, 10(2), 371-388.

Herrmann, M., Estournel, C., Adloff, F., \& Diaz, F. (2014). Impact of climate change on the northwestern Mediterranean Sea pelagic planktonic ecosystem and associated carbon cycle. Journal of Geophysical Research C: Oceans. https://doi.org/10.1002/2014JC010016

Ibanez, F., \& Dauvin, J.-C. (1988). Long-term changes (1977 to 1987) in a muddy fine sand Abra alba-Melinna palmata community from the Western English Channel: multivariate time-series analysis. Marine Ecology Progress Series, 65-81.

Josse, J., \& Husson, F. (2012). Handling missing values in exploratory multivariate data analysis methods. Journal de La Société Française de Statistique, 153(2), 79-99.

Katechakis, A., Stibor, H., Sommer, U., \& Hansen, T. (2004). Feeding selectivities and food niche separation of Acartia clausi, Penilia avirostris (Crustacea) and Doliolum denticulatum (Thaliacea) in Blanes Bay (Catalan Sea, NW Mediterranean). Journal of Plankton Research, 26(6), 589-603.

Kleiber, C., Hornik, K., Leisch, F., \& Zeileis, A. (2002). strucchange: An R package for testing for structural change in linear regression models. Journal of Statistical Software, $7(2), 1-38$.

Kudela, R. M., Cochlan, W. P., Peterson, T. D., \& Trick, C. G. (2006). Impacts on phytoplankton biomass and productivity in the Pacific Northwest during the warm ocean conditions of 2005. Geophysical Research Letters, 33(22).

Licandro, P, Braconnot, J. C., Carré, C., Dallot, S., Etienne, M., Ibanez, F., \& Moitié, M. (2001). Interannual variations of some species of gelatinous zooplankton Siphonophora and Thaliacea in a coastal long-term series in the North-Western Mediterranean. In 
Gelatinous zooplankton outbreaks: theory and practice. CIESM Workshop Ser (Vol. 14, pp. 51-52).

Licandro, Priscilla, Ibanez, F., \& Etienne, M. (2006). Long-term fluctuations (1974-99) of the salps Thalia democratica and Salpa fusiformis in the northwestern Mediterranean Sea: Relationships with hydroclimatic variability. Limnology and Oceanography, 51(4), 1832-1848.

Lombard, F., Boss, E., Waite, A. M., Vogt, M., Uitz, J., Stemmann, L., ... Picheral, M. (2019). Globally consistent quantitative observations of planktonic ecosystems. Frontiers in Marine Science, 6, 196.

Lynam, C. P., Llope, M., Möllmann, C., Helaouët, P., Bayliss-Brown, G. A., \& Stenseth, N. C. (2017). Interaction between top-down and bottom-up control in marine food webs. Proceedings of the National Academy of Sciences, 114(8), 1952-1957.

Mack, H. R., Conroy, J. D., Blocksom, K. A., Stein, R. A., \& Ludsin, S. A. (2012). A comparative analysis of zooplankton field collection and sample enumeration methods. Limnology and Oceanography: Methods, 10(1), 41-53.

Margirier, F., Testor, P., Heslop, E., Mallil, K., Bosse, A., Houpert, L., ... D’ortenzio, F. (2020). Abrupt warming and salinification of intermediate waters interplays with decline of deep convection in the Northwestern Mediterranean Sea. Scientific Reports, 10(1), 111.

Martin-Vide, J., \& Lopez-Bustins, J. (2006). The western Mediterranean oscillation and rainfall in the Iberian Peninsula. International Journal of Climatology: A Journal of the Royal Meteorological Society, 26(11), 1455-1475.

Martín, P., Sabatés, A., Lloret, J., \& Martin-Vide, J. (2012). Climate modulation of fish populations: the role of the Western Mediterranean Oscillation (WeMO) in sardine (Sardina pilchardus) and anchovy (Engraulis encrasicolus) production in the northwestern Mediterranean. Climatic Change, 110(3-4), 925-939.

Mazzocchi, M. G., Licandro, P., Dubroca, L., Di Capua, I., \& Saggiomo, V. (2011). Zooplankton associations in a Mediterranean long-term time-series. Journal of Plankton Research, 33(8), 1163-1181.

Medellín-Mora, J., Escribano, R., \& Schneider, W. (2016). Community response of zooplankton to oceanographic changes (2002-2012) in the central/southern upwelling system of Chile. Progress in Oceanography, 142, 17-29.

Molinero, J. C., Casini, M., \& Buecher, E. (2008b). The influence of the Atlantic and regional climate variability on the long-term changes in gelatinous carnivore populations in the 
northwestern Mediterranean. Limnology and Oceanography, 53(4), 1456-1467.

Molinero, J. C., Ibanez, F., Nival, P., Buecher, E., \& Souissi, S. (2005). North Atlantic climate and northwestern Mediterranean plankton variability. Limnology and Oceanography, 50(4), 1213-1220. https://doi.org/10.4319/lo.2005.50.4.1213

Molinero, J. C., Ibanez, F., Souissi, S., Buecher, E., Dallot, S., \& Nival, P. (2008a). Climate control on the long-term anomalous changes of zooplankton communities in the Northwestern Mediterranean. Global Change Biology. https://doi.org/10.1111/j.13652486.2007.01469.x

Pansera, M., Granata, A., Guglielmo, L., Minutoli, R., Zagami, G., \& Brugnano, C. (2014). How does mesh-size selection reshape the description of zooplankton community structure in coastal lakes? Estuarine, Coastal and Shelf Science, 151, 221-235.

Plounevez, S., \& Champalbert, G. (2000). Diet, feeding behaviour and trophic activity of the anchovy (Engraulis encrasicolus L.) in the Gulf of Lions (Mediterranean Sea). Oceanologica Acta, 23(2), 175-192.

Purcell, J. E. (2005). Climate effects on formation of jellyfish and ctenophore blooms: a review. Marine Biological Association of the United Kingdom. Journal of the Marine Biological Association of the United Kingdom, 85(3), 461.

Queiros, Q., Fromentin, J.-M., Astruc, G., Bauer, R. K., \& Saraux, C. (2018). Dolphin predation pressure on pelagic and demersal fish in the northwestern Mediterranean Sea. Marine Ecology Progress Series, 603, 13-27.

Queiros, Q., Fromentin, J.-M., Gasset, E., Dutto, G., Huiban, C., Metral, L., ... Saraux, C. (2019). Food in the Sea: size also matters for pelagic fish. Frontiers in Marine Science, 6,385 .

Raybaud, V., Nival, P., Mousseau, L., Gubanova, A., Altukhov, D., Khvorov, S., ... Andersen, V. (2008). Short term changes in zooplankton community during the summerautumn transition in the open NW Mediterranean Sea: species composition, abundance and diversity.

Romagnan, J.-B., Legendre, L., Guidi, L., Jamet, J.-L., Jamet, D., Mousseau, L., ... Sardet, C. (2015). Comprehensive model of annual plankton succession based on the wholeplankton time series approach. Plos One, 10(3), e0119219.

Romagnan, J. B., Aldamman, L., Gasparini, S., Nival, P., Aubert, A., Jamet, J. L., \& Stemmann, L. (2016). High frequency mesozooplankton monitoring: Can imaging systems and automated sample analysis help us describe and interpret changes in zooplankton community composition and size structure-An example from a coastal 

site. Journal of Marine Systems, 162, 18-28.

969

970

971

972

973

974

975

976

977

978

979

980

981

982

983

984

985

986

987

988

989

990

991

992

993

994

995

996

997

998

999

1000

1001

Rossi, N., \& Jamet, J.-L. (2009). Structure and succession of plankton communities in two Mediterranean neighbouring coastal ecosystems (Toulon bays, France). New Oceanography Research Developments, 1-14.

Rouyer, T., Fromentin, J.-M., Stenseth, N. C., \& Cazelles, B. (2008). Analysing multiple time series and extending significance testing in wavelet analysis. Marine Ecology Progress Series, 359, 11-23.

Sabatés, A., Martín, P., Lloret, J., \& Raya, V. (2006). Sea warming and fish distribution: the case of the small pelagic fish, Sardinella aurita, in the western Mediterranean. Global Change Biology, 12(11), 2209-2219.

Saraux, C., Van Beveren, E., Brosset, P., Queiros, Q., Bourdeix, J.-H., Dutto, G., ... Fromentin, J.-M. (2019). Small pelagic fish dynamics: A review of mechanisms in the Gulf of Lions. Deep Sea Research Part II: Topical Studies in Oceanography.

Scharf, F. S., Juanes, F., \& Rountree, R. A. (2000). Predator size-prey size relationships of marine fish predators: interspecific variation and effects of ontogeny and body size on trophic-niche breadth. Marine Ecology Progress Series, 208, 229-248.

Schwarz, G. (1978). Estimating the dimension of a model. Annals of Statistics, 6(2), 461-464.

Sheldon, R. W., Sutcliffe Jr, W. H., \& Paranjape, M. A. (1977). Structure of pelagic food chain and relationship between plankton and fish production. Journal of the Fisheries Board of Canada, 34(12), 2344-2353.

Siokou-Frangou, I., Christaki, U., Mazzocchi, M. G., Montresor, M., Ribera d'Alcalà, M., Vaqué, D., \& Zingone, A. (2010). Plankton in the open Mediterranean Sea: a review.

Sommer, U., Berninger, U. G., Böttger-Schnack, R., Cornils, A., Hagen, W., Hansen, T., ... Stibor, H. (2002a). Grazing during early spring in the Gulf of Aqaba and the northern Red Sea. Marine Ecology Progress Series, 239, 251-261.

Sommer, U., Gliwicz, Z. M., Lampert, W., \& Duncan, A. (1986). The PEG-model of seasonal succession of planktonic events in fresh waters. Arch. Hydrobiol, 106(4), 433-471.

Sommer, U., Stibor, H., Katechakis, A., Sommer, F., \& Hansen, T. (2002b). Pelagic food web configurations at different levels of nutrient richness and their implications for the ratio fish production: primary production. In Sustainable increase of marine harvesting: Fundamental mechanisms and new concepts (pp. 11-20). Springer.

Svensen, C., Seuthe, L., Vasilyeva, Y., Pasternak, A., \& Hansen, E. (2011). Zooplankton distribution across Fram Strait in autumn: Are small copepods and protozooplankton important? Progress in Oceanography, 91(4), 534-544. 
Tam, J., Taylor, M. H., Blaskovic, V., Espinoza, P., Ballón, R. M., Díaz, E., ... Ayón, P. (2008). Trophic modeling of the Northern Humboldt Current Ecosystem, part I: comparing trophic linkages under La Niña and El Niño conditions. Progress in Oceanography, 79(2-4), 352-365.

Thackeray, S. J., Sparks, T. H., Frederiksen, M., Burthe, S., Bacon, P. J., Bell, J. R., ... Carvalho, L. (2010). Trophic level asynchrony in rates of phenological change for marine, freshwater and terrestrial environments. Global Change Biology, 16(12), 33043313.

The MerMex Group, X. Durrieu de Madron, C. Guieu, R. Sempéré, P. Conan, D. Cossa, F. D’Ortenzio, C. Estournel, F. Gazeau, C. Rabouille, L. Stemmann, et al. (2011). Marine ecosystems' responses to climatic and anthropogenic forcings in the Mediterranean. Progress in Oceanography, 91(2), 97-166.

Tranter, D. J. (1968). Reviews on zooplankton sampling methods. Zooplankton Sampling. Monographs on Oceanographic Methodology. UNESCO, Paris.

Tsikliras, A. C. (2008). Climate-related geographic shift and sudden population increase of a small pelagic fish (Sardinella aurita) in the eastern Mediterranean Sea. Marine Biology Research, 4(6), 477-481.

Van Beveren, E, Fromentin, J. ., Rouyer, T., Bonhommeau, S., Brosset, P., \& Saraux, C. (2016a). The fisheries history of small pelagics in the Northern Mediterranean. ICES Journal of Marine Science. https://doi.org/10.1093/icesjms/fsw023

Van Beveren, E, Keck, N., Fromentin, J. ., Laurence, S., Boulet, H., Labrut, S., ... Saraux, C. (2016b). Can pathogens alter the population dynamics of sardine in the NW Mediterranean? Marine Biology. https://doi.org/10.1007/s00227-016-3015-7

Van Beveren, Elisabeth, Bonhommeau, S., Fromentin, J.-M., Bigot, J.-L., Bourdeix, J.-H., Brosset, P., ... Saraux, C. (2014). Rapid changes in growth, condition, size and age of small pelagic fish in the Mediterranean. Marine Biology. https://doi.org/10.1007/s00227014-2463-1

Van Beveren, Elisabeth, Fromentin, J.-M., Bonhommeau, S., Nieblas, A.-E., Metral, L., Brisset, B., ... Saraux, C. (2017). Predator-prey interactions in the face of management regulations: changes in Mediterranean small pelagic species are not due to increased tuna predation. Canadian Journal of Fisheries and Aquatic Sciences, 74(9), 1422-1430.

Van der Lingen, C. D., Hutchings, L., \& Field, J. G. (2006). Comparative trophodynamics of anchovy Engraulis encrasicolus and sardine Sardinops sagax in the southern Benguela: are species alternations between small pelagic fish trophodynamically mediated? African 
Vandromme, P., Lars, S., Garcìa-Comas, C., Berline, L., Sun, X., \& Gorsky, G. (2012). Assessing biases in computing size spectra of automatically classified zooplankton from imaging systems: A case study with the ZooScan integrated system. Methods in Oceanography. https://doi.org/10.1016/j.mio.2012.06.001

Vandromme, P., Nogueira, E., Huret, M., Lopez-Urrutia, A., González-Nuevo González, G., Sourisseau, M., \& Petitgas, P. (2014). Springtime zooplankton size structure over the continental shelf of the Bay of Biscay. Ocean Science, 10(5), 821-835.

Vandromme, P., Stemmann, L., Berline, L., Gasparini, S., Mousseau, L., Prejger, F., ... Gorsky, G. (2011). Inter-annual fluctuations of zooplankton communities in the Bay of Villefranche-sur-mer from 1995 to 2005 (Northern Ligurian Sea, France). Biogeosciences, 8(11), 3143-3158.

Véron, M., Duhamel, E., Bertignac, M., Pawlowski, L., \& Huret, M. (2020). Major changes in sardine growth and body condition in the Bay of Biscay between 2003 and 2016: Temporal trends and drivers. Progress in Oceanography, 182, 102274.

Wahlström, E., Persson, L., Diehl, S., \& Byström, P. (2000). Size-dependent foraging efficiency, cannibalism and zooplankton community structure. Oecologia, 123(1), 138148.

Winder, M., Berger, S. A., Lewandowska, A., Aberle, N., Lengfellner, K., Sommer, U., \& Diehl, S. (2012). Spring phenological responses of marine and freshwater plankton to changing temperature and light conditions. Marine Biology, 159(11), 2491-2501.

Zhou, M., Carlotti, F., \& Zhu, Y. (2010). A size-spectrum zooplankton closure model for ecosystem modelling. Journal of Plankton Research. https://doi.org/10.1093/plankt/fbq054

Zuur, A. F., Ieno, E. N., \& Elphick, C. S. (2010). A protocol for data exploration to avoid common statistical problems. Methods in Ecology and Evolution, 1(1), 3-14. 